\title{
Venous hemodynamics in neurological disorders: an analytical review with hydrodynamic analysis
}

\author{
Clive B Beggs
}

\begin{abstract}
Venous abnormalities contribute to the pathophysiology of several neurological conditions. This paper reviews the literature regarding venous abnormalities in multiple sclerosis (MS), leukoaraiosis, and normal-pressure hydrocephalus (NPH). The review is supplemented with hydrodynamic analysis to assess the effects on cerebrospinal fluid (CSF) dynamics and cerebral blood flow (CBF) of venous hypertension in general, and chronic cerebrospinal venous insufficiency (CCSVI) in particular.

CCSVI-like venous anomalies seem unlikely to account for reduced CBF in patients with MS, thus other mechanisms must be at work, which increase the hydraulic resistance of the cerebral vascular bed in MS. Similarly,

hydrodynamic changes appear to be responsible for reduced CBF in leukoaraiosis. The hydrodynamic properties of the periventricular veins make these vessels particularly vulnerable to ischemia and plaque formation.

Venous hypertension in the dural sinuses can alter intracranial compliance. Consequently, venous hypertension may change the CSF dynamics, affecting the intracranial windkessel mechanism. MS and NPH appear to share some similar characteristics, with both conditions exhibiting increased CSF pulsatility in the aqueduct of Sylvius. CCSVI appears to be a real phenomenon associated with MS, which causes venous hypertension in the dural sinuses. However, the role of CCSVI in the pathophysiology of MS remains unclear.
\end{abstract}

Keywords: Venous hypertension, CCSVI, Multiple sclerosis, Leukoaraiosis, Normal-pressure hydrocephalus, Cerebral blood flow, Cerebrospinal fluid

\section{Introduction}

The cerebral venous system is often viewed simply as a series of collecting vessels channeling blood back to the heart, yet it also plays an important role in the intracranial hemodynamic/cerebrospinal fluid (CSF) regulatory system (hereafter simply referred to as the hydrodynamic regulatory system), a role that is often overlooked and that appears to influence both perfusion of the brain parenchyma [1,2] and the dynamics of the CSF system [3-5]. Although the physiological mechanisms associated with cerebral-venous outflow are poorly understood, abnormalities of the venous system have been implicated in a variety of neurological disorders, including multiple sclerosis (MS) [4,6-11], leukoaraiosis [3,12-16], vascular dementia [5,17], and normal-pressure hydrocephalus (NPH) $[2,3]$. This raises intriguing questions about the involvement of the venous system in these

Correspondence: c.b.beggs@bradford.ac.uk

Medical Biophysics Laboratory, School of Engineering, Design and Technology, University of Bradford, Bradford, West Yorkshire BD7 1DP, UK pathophysiologies. Furthermore, similarities between the intracranial hydrodynamic phenomena associated with these conditions suggest that common physiological mechanisms may be at work. This paper reviews the literature relating to the role of the venous system in MS, leukoaraiosis, and NPH, with the aim of better understanding the contribution of venous hemodynamics to these neurological disorders.

\section{Evidence of venous involvement}

Despite having very different pathologies, MS, leukoaraiosis, and NPH all share some common characteristics. In all three conditions, cerebral blood flow (CBF) is reduced [18-21]. Both MS [6,10] and leukoaraiosis $[13,14,22,23]$ are characterized by changes in the white matter (WM) in the periventricular region, and enlarged lateral ventricles are associated with both MS [24,25] and NPH [26,27]. Furthermore, some clinical characteristics are also shared. Gait disturbances [28-31], reduced cognitive ability $[30,32,33]$, and loss of bladder control 
[30,34,35] have been reported for all three conditions. This suggests that the pathophysiology of these disparate conditions might share a common feature. Having said this, all three diseases display marked pathophysiological differences. For example, MS is an autoimmune disease, characterized by brain atrophy [36,37], and it is thought that this is primarily responsible for ventricular enlargement [24,25]. Although the ventricles are also enlarged in NPH, brain parenchymal atrophy is not evident [26], and a measure of ventricular normality can sometimes be restored by the surgical insertion of a shunt to drain away excess CSF $[27,38,39]$. Although MS and leukoaraiosis both exhibit periventricular WM changes, leukoaraiosis is thought to be one presentation of cerebral small-vessel disease [40], whereas MS is a chronic inflammatory demyelinating disease of the central nervous system (CNS) [41]. Consequently, MS therapies focus on preventing axonal demyelination and promoting remyelination $[42,43]$, whereas vigorous treatment of cardiovascular risk factors has been advocated to prevent the development of leukoaraiosis, and to reduce the attendant risk of stroke and dementia [44].

\section{Multiple sclerosis}

Since the earliest years of research into MS, there has been suspicion that the venous system might be involved in its etiology, with Dawson [10], Putnam [6,11] and others [45-49] all implicating veins in the pathophysiology of the disease. MS plaques are often venocentric, and frequently form around the periventricular veins [6]. Dawson [10] reported that finger-like plaques form at the junction of the subependymal and medullary veins in the periventricular WM. Putnam and Adler [6], commenting on the appearance of these 'Dawson's fingers', observed that the medullary veins were enclosed in a sleeve of plaque, and that, adjacent to the plaques, the veins were grossly distorted and distended. Others [45,50-52] have also shown that inflammatory lesions tend to form axially around veins in the WM, with Tallantyre et al. [53] finding 80\% of MS lesions to be perivenous in nature. Kidd et al. [50] showed that lesions in the grey matter (GM) are also associated with veins, with the majority of cortical lesions arising within the territory of the principal vein, $V_{5}$, whose course begins in the WM [54], and the remaining cortical lesions forming in the region drained by its branches or those of the superficial veins. Others have confirmed these observations, finding intracortical [55-57], leucocortical [55], and sub-cortical [52] lesions to be perivenous. However, the connection with the venous system has largely been ignored, with the focus of MS research turning instead towards the involvement of the immune system in the disease $[58,59]$.
Recently, there has been renewed interest in studying vascular changes associated with MS [60-62]. This has been precipitated by the controversial finding that abnormalities in the extracranial venous system appear to be associated with the disease $[4,7,8,63]$. This condition, known as chronic cerebrospinal venous insufficiency (CCSVI), is characterized by multiple intraluminal stenotic malformations of the principal venous-drainage pathways, particularly in the internal jugular veins (IJVs) and the azygos vein, and has been shown to be associated with impaired blood flow from the brain to the heart in patients with MS [8], with the hydraulic resistance of the cerebral-venous drainage system being on average $63.5 \%$ greater in CCSVI-positive individuals [64]. CCSVI also appears to be associated with changes in the intracranial vasculature, with a strong correlation shown between CCSVI severity and decreased CBF in both the WM and GM of patients with MS [65]. In addition, Zivadinov et al. [9] reported a marked reduction in venous vasculature visibility (VVV) on susceptibilityweighted imaging (SWI) for cerebral veins of less than $0.3 \mathrm{~mm}$ diameter in patients with MS compared with controls, a phenomenon that is strongly statistically associated with CCSVI $(P<0.0001)$. This finding appears to corroborate the work of Ge et al. [66]. However, unlike Ge et al., who attributed the reduction in VVV to hypometabolic status in the brain parenchyma of patients with MS, Zivadinov et al. performed a precontrast and post-contrast SWI venography experiment, which indicated the reduction in VVV to be due to morphological changes in the cerebral veins of patients with MS. Indeed, such was the clear-cut nature of these venous changes that Beggs et al. [67] were able to distinguish between patients with MS and healthy controls with $100 \%$ accuracy using cerebral-venous data alone.

These findings reinforce a large body of evidence connecting MS with alterations in the cerebral vascular bed. Using tomography, a number of early investigators [68-71], found reduced CBF in the GM and WM of patients with MS. However, this work received little attention and it was not until the advent of magnetic resonance imaging (MRI) that interest was renewed [61]. Using dynamic susceptibility contrast-enhanced MRI, Law et al. [18], identified a 53.4\% decrease in CBF throughout the normal-appearing white matter (NAWM) in patients with relapsing-remitting (RR) MS compared with controls. This was accompanied by a twofold increase in vascular mean transit time (MTT), and a $13.6 \%$ decrease in WM cerebral blood volume (CBV). Adhya et al. [21] studied tissue perfusion in the NAWM of patients with primary progressive MS, relapsing-remitting (RR) MS, and healthy controls. They also found CBF and CBV to be significantly decreased in all NAWM regions in both forms of MS compared with controls. Similarly, Ge et al. [19] 
found reduced CBF with significantly prolonged MTT in the NAWM to be a feature of MS. Varga et al. [20] reported blood flow to be particularly low in the periventricular region, with CBF in the NAWM in this region being significantly lower in patients with MS compared with controls. Interestingly, they also found CBF to be decreased in the sub-cortical normal-appearing grey matter in patients with RR MS, suggesting a continuum of decreased tissue perfusion, beginning in the WM and spreading to the GM as the disease progresses [60]. Collectively, these findings indicate that hypoperfusion of the WM is a consistent phenomenon in MS, whatever the disease subtype [61]. Several researchers have also found MS to be associated with reduced CBF in the GM. Rashid et al. [72] found hypoperfusion in several cortical areas of patients with RR and progressive MS. Investigating tissue perfusion in the thalamus, putamen, and caudate nuclei of patients with MS, Inglese et al. [73] found a decrease in CBF in the deep GM, the magnitude of which increased with the severity of the disease. These findings, along with those relating to the WM, suggest that MS is associated with systemic changes in blood flow through the cerebral vascular bed, something highlighted by Mancini et al. [74], who found the mean tissue-vein transit time to be 3.2 seconds in patients with MS, compared with only 2.9 seconds in healthy controls.

Venous hypertension in the dural sinuses is known to inhibit absorption of CSF through the arachnoid villi (AV) [75,76]. Zamboni et al. [4] reported reduced CSF net flow and increased CSF pulsatility in the aqueduct of Sylvius (AoS) in patients with MS, and found this to be strongly associated with CCSVI severity. Magnano et al. [77] also found MS to be strongly associated with increased aqueductal pulsatility and reduced CSF net flow. Although Magnano et al. did not specifically consider CCSVI, their findings are consistent with those of Zamboni et al., and suggest that venous hypertension may be a feature of MS. Abnormal CSF hydrodynamics have also been implicated in the formation of cortical lesions in MS. Sub-pial lesions, which appear not to be perivenous, cover extensive areas of the cortex, and extend from the surface into the brain [55]. They appear to be mediated by infiltrates, generated by inflammatory cells in the meninges or the CSF, which diffuse inwards from the surface of the brain [55,78]. Kutzelnigg et al. [79] found sub-pial demyelination to be most pronounced within deep invaginations of the cortex, and suggested that this reflected regional differences in CSF flow, with extensive demyelination occurring in areas of CSF stasis.

\section{Leukoaraiosis}

Leukoaraiosis is a radiological finding, characterized by WM hyperintensities in the periventricular region on
T2-weighted MRI scans [80], which is associated with diverse clinical symptoms, including cognitive impairment [81], vascular dementia [82,83], gait disturbance [30], and enhanced risk for stroke [84]. Although leukoaraiosis is primarily a pathology associated with aging $[83,85]$, it shares several similarities with MS $[62,86,87]$. Both diseases affect the WM and are associated with demyelination [13,82]. In a similar manner to MS, leukoaraiosis is characterized by WM morphological changes around the periventricular veins [13,14,22,23]. Although not fully understood, leukoaraiosis is thought to be associated with chronic cerebral ischemia [88]. In cases of hypoxic/ischemic injury, histological changes of the WM can range from coagulative necrosis and cavitation to non-specific tissue changes such as sponginess, patchy demyelination, and astrocytic proliferation [88]. Such changes are consistent with the lesions seen in patients with leukoaraiosis [89], suggesting that ischemia is closely associated with the condition [88]. In particular, leukoaraiosis is characterized by non-inflammatory collagenosis of the periventricular veins [13,22], resulting in thickening of the vessel walls and narrowing, or even occlusion, of the lumen [13]. Moody et al. [13] found a strong association between the probability of severe leukoaraiosis and periventricular venous collagenosis (PVC).

Mirroring the cerebral hemodynamics of MS, several researchers have reported leukoaraiosis to be associated with reduced CBF $[23,83,90,91]$. However, unlike MS, a strong epidemiological link exists between leukoaraiosis and cerebrovascular disease [92-94]. Arterial hypertension and cardiac disease are also risk factors that are frequently associated with leukoaraiosis [88], and these are thought to induce arteriolosclerotic changes in the arteries and arterioles of the WM, replacing the smooth muscle cells by fibro-hyaline material, causing thickening of the vessel walls and narrowing of the vascular lumen [95]. Indeed, arteriolosclerosis is often present within areas of leukoaraiosis [96,97]. Furthermore, the arterioles supplying the deep WM, which are some of the longest in the brain, frequently become tortuous with aging [23,98-100], with the result that there is a trend towards increased tortuosity in individuals with leukoaraiosis [23]. This tortuosity usually begins abruptly as the arteriole passes from the cortex into the WM [23], and greatly increases the vessel length. Given that this will increase the hydraulic resistance of the arterioles [99], it will tend to inhibit the blood flow to the deep WM. It is therefore perhaps not surprising that the periventricular veins, being a 'distal irrigation field' [88], are prone to ischemic damage under conditions of moderate deficit in blood flow.

Further evidence linking leukoaraiosis with altered venous hemodynamics comes from a series of studies by Chung and co-workers $[15,16,101]$, who investigated 
jugular venous reflux (JVR) (that is, retrograde flow in the IJVs) in older individuals. They found JVR to be a phenomenon that increased with age, and concluded that it was associated with more severe age-related WM changes (leukoaraiosis) [16]. In particular, they found that the IJV lumen cross-sectional area increased with age [101], which suggests dilation of the veins due to increased venous pressure and reduced flow velocity. Chung et al. [101] suggested that if the venous hypertension exceeds the ability of the dilation to compensate for the additional pressure, then it would compromise the competence of the jugular venous valves, with the result that the direction of venous flow could be reversed. They further hypothesized that this 'chronic or longterm episodic elevated cerebral-venous pressure might cause cerebral venule hypertension, resulting in... reduce[d] CBF since elevated cerebral venule pressure would lower cerebral perfusion pressure' [15].

In a series of studies, Bateman and co-workers investigated altered venous hemodynamics in a variety of neurological conditions $[2,3,5,17,102,103]$. In particular, they investigated pulsatile blood flow in leukoaraiosis [3] and vascular dementia [5]. In both conditions, they found venous pulsatility to be greatly increased in the straight sinus compared with healthy controls, implying that in individuals with leukoaraiosis and vascular dementia, the blood flow through the WM is highly pulsatile. Given that blood flow through the cerebral vascular bed is generally non-pulsatile in healthy young adults $[3,104]$, Bateman's findings imply marked changes in hemodynamic behavior in individuals with leukoaraiosis and vascular dementia, something that will induce transient shear stresses on the endothelia. Given that vessels experiencing highly oscillatory flows also seem to be at high risk of developing arteriosclerosis [105], it is perhaps not surprising that leukoaraiosis is associated with morphological changes in the WM vasculature $[13,14,22,23]$. Bateman hypothesized that the increased pulsatility exhibited by the CBF was a direct consequence of a dysfunctional windkessel mechanism [3,5], implying profound alterations in the dynamics of the CSF system. Indeed, Bateman calculated the CSF pulse volume in severe cases of leukoaraiosis to be $46 \%$ greater than that in healthy controls [3]. Furthermore, he found that the CSF dynamics associated with leukoaraiosis delayed the egress of blood from the cortical veins into the superior sagittal sinus (SSS), inducing a complex pulse wave, which propagated backwards towards the capillaries of the cortex [3].

\section{Normal-pressure hydrocephalus}

$\mathrm{NPH}$ occurs when there is an abnormal accumulation of CSF in the ventricles, causing them to become enlarged [27], but with little or no increase in intracranial pressure (ICP). Most adults with the condition experience an ICP that is not unusually high, being generally less than $15 \mathrm{mmHg}[106,107]$. NPH is characterized by gait disturbance, urinary incontinence, and dementia [108]. Although its pathophysiology is poorly understood, NPH has traditionally been thought to be a form of communicating hydrocephalus, characterized by poor absorption of CSF into the SSS due to defective AV [109]. However, evidence supporting this opinion is lacking [109], and several commentators have suggested alternative theories [2,102,110-112]. In particular, there is growing evidence that reduced intracranial compliance $[2,102,113,114]$, induced by venous hypertension, might be involved in the pathophysiology of NPH $[2,102,115,116]$, although this opinion is disputed by others $[26,117,118]$. Bateman [102] found the arteriovenous delay (AVD), a general marker of intracranial compliance, to be $53 \%$ lower in patients with NPH compared with healthy controls. A similar reduction in AVD in patients with NPH was reported in a subsequent study [2]. Mase et al. [114] independently confirmed this finding, showing a $64 \%$ reduction in intracranial compliance in patients with NPH compared with controls. The fact that an AVD exists at all indicates the presence of compressible material within the intracranial space, which is deformed when the systolic arterial pulse enters the cranium. With respect to this, the cerebral veins are a likely candidate $[115,116]$. Approximately $70 \%$ of intracranial blood volume is located within the venous compartment, much of it in thin-walled veins that readily collapse under small changes in transmural pressure. Given that the intracranial veins, particularly those of the superficial venous system, are much more compliant than the arterial vessels, it has been suggested that the change in intracranial compliance seen in patients with NPH may be associated with venous hypertension [2]. In patients with $\mathrm{NPH}$, cortical-vein compliance is significantly reduced [102]; however, following shunt surgery, compliance greatly increases, suggesting that the compliance changes associated with these veins are functional and not structural $[2,102]$. NPH has been shown to be associated with venous hypertension in the SSS [119]. It is therefore plausible that hypertension in the SSS might increase the pressure in the cortical veins, with the result that the functional compliance of these vessels is reduced [2]. Furthermore, venous hypertension in the SSS would tend to reduce the compliance of the $\mathrm{AV}$, and this, together with reduced cortical-vein compliance, might account for the reduction in AVD seen in individuals with NHP.

CBF has been found to be lower in patients with NPH than in normal controls [120-123]. This is generally thought to be associated with the formation of ischemic lesions, particularly in the deep WM [118,122,124], 
implying that regional differences in CBF might exist in individuals with NPH. Momjian et al. [122] found the distribution of regional CBF in the WM to be different in patients with NPH compared with healthy controls, with a more pronounced $\mathrm{CBF}$ reduction adjacent to the lateral ventricles, and a logarithmic normalization occurring with distance from the ventricles. These findings built on an earlier study by Owler et al. [121], who reported NPH to be associated with a marked reduction in mean CBF in the deep GM. Momjian et al. [122] attributed these phenomena to a combination of factors, including cerebral small-vessel disease; tissue distortion, and reversal of CSF and interstitial fluid flow, resulting in reduced cerebral perfusion pressure (CPP) near the ventricles and resultant ischemia. However, this interpretation was challenged by Bateman [102], who found blood flow in the straight sinus, which serves the periventricular region, to be unchanged in patients with $\mathrm{NPH}$ compared with controls. Having said this, Bateman also reported $27 \%$ less drainage from the SSS in patients with NHP compared with healthy controls. Although Bateman's findings concerning the blood flow through the deep venous system are difficult to explain, those relating to the superficial venous system, might help to explain the formation of cortical infarcts in patients with NPH reported by Tullberg [124].

A number of researchers have reported marked alterations in CSF dynamics in NPH, with CSF pulsatility in the AoS found to be markedly greater in patients with $\mathrm{NPH}$ compared with controls [112,125-129]. This mirrors the findings of Magnano et al. [77], who found a similar phenomenon in patients with MS. By contrast, the cervical CSF pulse was either unchanged [112] or actually reduced in individuals with NPH compared with controls [126]. Although the reasons for this apparent paradox are difficult to explain, it suggests that biomechanical changes occur with NPH, which alter both intracranial compliance and pulsatility of the cerebral venous and arterial blood flows. NPH also appears to be associated with significantly reduced CSF resorption into the SSS through the AV [26,130], which is a finding consistent with venous hypertension in the dural sinuses. Drainage of CSF into the dural venous sinuses requires a pressure gradient between the sub-arachnoid space (SAS) and the SSS of about 5 to $7 \mathrm{mmHg}[131,132]$. If the pressure in the SSS is increased, then either the ICP must also increase to facilitate CSF absorption through the AV [117], or alternatively the CSF must be absorbed elsewhere in the intracranial space. Given that ICP does not substantially increase in individuals with $\mathrm{NPH}$, this indicates that CSF is being resorbed elsewhere [124]. Bateman [102] suggested that CSF resorption is likely to occur in the sub-ependymal brain parenchyma. Ventricular reflux of fluid has been shown to be a characteristic of communicating hydrocephalus $[133,134]$, with the periventricular tissue characterized by disruption of the ependyma, and by edema, neuronal degeneration, and ischemia [124]. Although the hydrodynamics associated with ventricular reflux are poorly understood, it may be that reduced CSF absorption by the AV in individuals with $\mathrm{NPH}$ at least partly explains the increase in aqueductal CSF pulsatility that is associated with the condition [133].

\section{Mass transfer and spatial proximity}

Although there are clear differences in the pathologies of MS, leukoaraiosis and $\mathrm{NPH}$, there are also striking similarities. All three are characterized by: 1) WM changes in the periventricular region; and 2) reduced CBF. The lesions associated with both MS and leukoaraiosis tend to be perivenous in nature, and the changes in CSF dynamics associated with NPH and MS also reveal similarities. This raises intriguing questions as to why these similarities exist. Are there some underlying physical mechanisms that are common to all these conditions?

The proximity of immune-cell aggregations to the vasculature is a hallmark of MS [135]. Whereas much attention has been paid to the biological mechanisms involved in the formation of MS plaques, the implications associated with their spatial arrangement have largely been ignored. Why do MS plaques form next to veins rather than capillaries, and why do they consistently occur in some places and not others? In nature, when a process is truly random, events tend to be widely distributed, with no underlying pattern. Conversely, if there is an underlying phenomenon, then the events will tend to cluster in both time and space. The fact that MS plaques consistently form around the periventricular [136] and cortical [50] veins indicates that the latter, rather than the former process must be taking place. If this were not so, then lesions would be randomly distributed throughout the brain parenchyma. From this, it can be concluded that in MS some unknown, but consistent, phenomenon is at work, which causes plaques to form around certain cerebral veins. Although historically considered a disease primarily affecting the WM, it is now known that cortical demyelination is common in MS and more extensive than previously appreciated $[78,137]$. Although it has been reported that many intra-cortical and sub-cortical lesions are perivenous in nature [50,52,55-57], it is not known why this is so. However, the fact that MS plaques form in the vicinity of veins in both the deep and superficial systems suggests that the pathophysiological mechanisms at work are extensive and not confined to a focal region.

Another universal principle found in nature is that of mass transfer. In simple terms, in order for matter to move from one place to another, it must be transported by some mechanism. In biology, the transport of cells 
and chemicals generally occurs either by: diffusion, by active transport (in the case of ion transport across the cell membrane), or through transport in a bulk fluid such as blood. If diffusion or active transport are the mechanisms at work, then there is a tendency towards higher concentrations of the transported substance near its source and lower concentrations further away. If this simple logic is applied to the formation of perivenous MS lesions, it would suggest that the plaque formation emanates from the blood vessels, rather than the other way round. Indeed, the current thinking appears to support this, suggesting that in MS, plaque formation is precipitated by breaching of the blood-brain barrier (BBB) $[51,138,139]$. If the diffusion principle is applied to the observation by Momjian et al. [122] that in patients with $\mathrm{NPH}$ the CBF steadily increases the further away from the lateral ventricles, then it suggests that the unknown factor inhibiting blood flow is emanating from the lateral ventricles, which suggests that ventricular fluid reflux might be involved.

The mass transport associated with bulk fluids also appears to offer insights into the spatial arrangement of ischemic WM changes, such as those found in leukoaraiosis. Considering oxygen transport in the blood through the cerebral vascular bed, the law of mass transport dictates that as oxygen is supplied to the brain parenchyma, so the oxygen levels in the blood will decrease. Consequently, the oxygen tension in the cerebral arteries will be higher than that in the cerebral veins. Under normal circumstances, this should not cause any problems, but when CBF is greatly impaired, as in both leukoaraiosis $[23,83,90,91]$ and MS [18-21], then this might create pathogenic conditions in the distal veins. If the oxygen consumption of the endothelia and brain parenchyma surrounding the arterioles and capillary bed is not downregulated, then the oxygen tension in the veins might become so low that ischemic damage could occur in these vessels. With respect to this, the periventricular WM, being at the distal end of the circuit [88], appears to be particularly vulnerable to ischemic damage when blood flow is reduced. If ischemic damage due to hypoperfusion is involved in the formation of MS lesions, as some have suggested [60,61], then this might explain why plaques tend to form around the veins, rather than the capillaries and arterioles.

\section{Hypoxia}

There is increasing evidence that hypoxia-like metabolic injury may be a pathogenic component in the formation of MS lesions [62,86]. Wakefield et al. [140] found morphological changes in the venous endothelia, which progressed to occlusive vascular inflammation. They proposed that these changes were the precursor to lesion formation, and suggested that demyelination in MS may have an ischemic basis. Aboul-Enein and Lassmann [141] reported similarities between the tissue injury found in inflammatory brain lesions and that found in hypoxic conditions of the CNS. Ge et al. [142] identified subtle venous wall signal changes in small MS lesions, which they interpreted as early-stage vascular changes. These changes may be the result of early ischemic injury, marking the beginning of trans-endothelial migration of vascular inflammatory cells, before any apparent BBB breakdown. Further evidence that focal inflammatory BBB leakage may not be the initiating event in MS plaque formation comes from Werring et al. [143], who measured random motion of water molecules (apparent diffusion coefficient; ADC) in the NAWM of patients with MS. They found that the formation of lesions was preceded by subtle progressive alterations in tissue integrity. Similarly, Wuerfel et al. [144] found that changes in perfusion parameters (CBF, CBV and MTT) were detectable not only prior to BBB breakdown, but also prior to increases in the ADC. They concluded that in MS, inflammation is accompanied by altered local perfusion, which can be detected prior to permeability of the BBB. Commenting on this, D'haeseleer et al. [60] concluded that 'focal ischaemia might play a part in the development of a subcategory of focal MS lesions'. Lochhead et al. [145], using a rat model, showed that hypoxia followed by re-oxygenation altered the conformation of the occlusion in the tight junctions between the endothelial cells, resulting in increased BBB permeability. In doing so, they confirmed the findings of earlier studies undertaken by the same team $[146,147]$. The earliest detectable event in the development of WM lesions is thought to be an increase in the permeability of the BBB [51], followed by inflammation and demyelination. Others have implicated tight-junction abnormalities in increased $\mathrm{BBB}$ permeability and lesion formation in MS $[139,148,149]$.

Several researchers have found similarities between leukoaraiosis and MS $[60,61]$. Leukoaraiosis is characterized by periventricular hyperintensities [80] and reduced CBF in the WM [150]. Its clinical symptoms include cognitive features that are similar to those associated with MS [151]. Graumann et al. [152], investigating gene expression in the NAWM of patients with secondary progressive MS and healthy controls, showed that the patients with MS exhibited consistent differences in the expression of hypoxia-inducible factor (HIF)-1a compared with controls. Similar upregulation of HIF-1a in cerebral WM was found by Fernando et al. [153] to be associated with leukoaraiosis, which they attributed to WM hypoperfusion. Leukoaraiosis is associated with significantly decreased CBF in the deep WM [150], and it is thought that ischemia, resulting from poor perfusion, is a major contributing factor $[12,13,22]$. The condition 
is characterized by non-inflammatory PVC, resulting in thickening of the vessel walls and narrowing of the deep cerebral veins $[13,22]$, which will inevitably increase the hydraulic resistance of these pathways. Although lumenal narrowing of the periventricular veins has not been reported in patients with MS, Putnam and Adler [6] reported that the periventricular MS plaques resulted in gross distension of the medullary veins upstream of the lesions, suggesting that venous stenosis is occurring. This would inevitably increase the hydraulic resistance of these vessels and promote hypoperfusion. Given that the perfusion pressure, which promotes blood flow, is relatively low in the periventricular veins, the WM in this region is particularly sensitive to fluctuations in total CBF [154]. Any increase in the hydraulic resistance of the periventricular veins might cause shunting of blood away from these vessels $[22,155]$, an action that would also tend to promote ischemia.

\section{Venous architecture}

So why should some regions of the brain be more vulnerable than others to damage? Perhaps the architecture of the cerebral-venous system provides some clues? While the distal venous regions may be prone to hypoxic stress, the spatial arrangement of the veins may also contribute to their vulnerability. Evidence in support this opinion comes from Schlesinger [155], who forced hot carmine-gelatin solution, under high pressure, into the vein of Galen in human cadaver brains. The extravasations that were produced, chiefly in the region of the angle of the lateral ventricle, 'closely resembled the distribution and shape of plaques in advanced cases of MS'. From this, Schlesinger concluded that: it seems possible that the plaques may only be found in this area of the ventricular wall because they have a definite topographical relationship to the veins which are crowded together in the region of the lateral ventricular angle.' Although the physiological implications of Schlesinger's experiment are debatable, his results are clear and unambiguous from a fluid-mechanics point of view. When the gelatin solution was forced into the deep venous system, it divided and flowed up the two internal cerebral veins, so that both hemispheres of the brain were affected. Furthermore, the fluid flowed relatively easily until it came to the junction between the medullary and subependymal veins, where the resistance was so great that the pressure built up to such an extent that the fluid burst through the vessel wall. The experiment therefore indicates two things: first, that the junction between the medullary and sub-ependymal veins has a much higher resistance to fluid flow than the downstream veins; and second, that the vessel walls at this junction are susceptible to rupture if the pressure gets too high.
The finding that the junction between the medullary and sub-ependymal veins has a high resistance to fluid flow is no surprise. The sub-ependymal veins are collecting vessels, which receive venous blood from a large number of the smaller medullary veins that enter the sub-ependymal veins at approximately 90 degrees. From a fluid-mechanics point of view, this is not a very streamlined configuration, and will result in relatively large pressure drop across this junction. Any stenosis at this junction would therefore greatly increase its resistance, possibly leading to distension of the upstream medullary veins, as Putnam and Adler reported [6]. Consequently, the periventricular veins share characteristics normally associated with developmental venous anomalies (DVAs). DVAs are a venous confluence in which a single collecting vessel drains an abnormally large venous territory, resulting in a relative volume overload. This anatomic configuration, as San Millán Ruíz et al. [156] pointed out, is similar to that encountered in the periventricular region. In addition, DVAs have been shown to have thickened walls [156], similar to those associated with PVC $[13,22]$, with stenosis of the collecting vein reported in $13.1 \%$ of patients [156]. Stenosis of this kind invariably increases the hydraulic resistance of the vein, so that the upstream pressure is greatly increased, as was shown by Dillon [157], who measured a $15 \mathrm{mmHg}$ pressure gradient across a stenosis of the collecting vein of a DVA in one patient.

Unlike the deep venous system, the superficial system has thin-walled cortical bridging veins that traverse the SAS. Blood flow through these compliant vessels is controlled by sphincters, which regulate discharge into the SSS $[158,159]$. This means that these vessels possess characteristics similar to those of a Starling resistor [160-163], and these collapse, occluding the blood flow, when the transmural pressure reaches a certain threshold [164]. The cortical bridging veins are very sensitive to small changes in transmural pressure. Indeed, because they are required to 'open' and 'close' to regulate blood flow from the cortex, the cortical venous pressure is only about 2 to $5 \mathrm{mmHg}$ higher than the ICP [164]. This means that small changes in ICP or venous pressure can have a substantial effect on the behavior of blood flow from the cortex. Indeed, it has been estimated that a change of as little as $1.5 \mathrm{mmHg}$ in the difference between ICP and the pressure in the bridging veins could be responsible for the difference between severe hypere$\mathrm{mia}(\mathrm{CBF}=1000 \mathrm{ml} / \mathrm{min})$ to serve ischemia $(\mathrm{CBF}=$ $300 \mathrm{ml} / \mathrm{min}$ ) [164]. Given that MS may be associated with venous hypertension in the dural sinuses of greater than $2 \mathrm{mmHg}$ [165], it can be hypothesized that this could have a profound effect on blood flow in the cortex. Although it is difficult to say how this might influence hemodynamic behavior in the cortex, it is notable that 
Kidd et al. [50] found GM lesions in patients with MS to be exclusively located adjacent to cortical veins. Drawing an analogy with WM lesions, they stated; 'We have been able to show that there is a clear relationship between the site and characteristics of cortical lesions and the five different types of cortical vein, just as Dawson's 'fingers' arise adjacent to veins in periventricular WM' [50].

\section{Cerebrospinal fluid dynamics and venous hypertension}

MS, leukoaraiosis, and NPH all appear, to a greater or lesser extent, to be associated with marked changes in the dynamics of the intracranial CSF system. This suggests that these diseases might be associated with alterations in the intracranial hydrodynamic regulatory system, which controls the volume and pulsatility of the blood in the cerebral vascular bed $[3,166,167]$. The interactions between the CBF and CSF are illustrated in Figure 1, which shows an idealized model of the principal intracranial fluid pathways. From this, it can be seen that there is a bulk flow of CSF from the choroid plexus to the SSS, via the AV, driven by the pressure gradient between the two. There is also a complex windkessel mechanism that ensures Monro-Kellie homeostasis, which compensates for transient increases in CBV by pushing CSF out of the cranium [168]. This sophisticated windkessel mechanism uses the CSF to dampen the arterial pulse and to ensure, in healthy young adults, the smooth

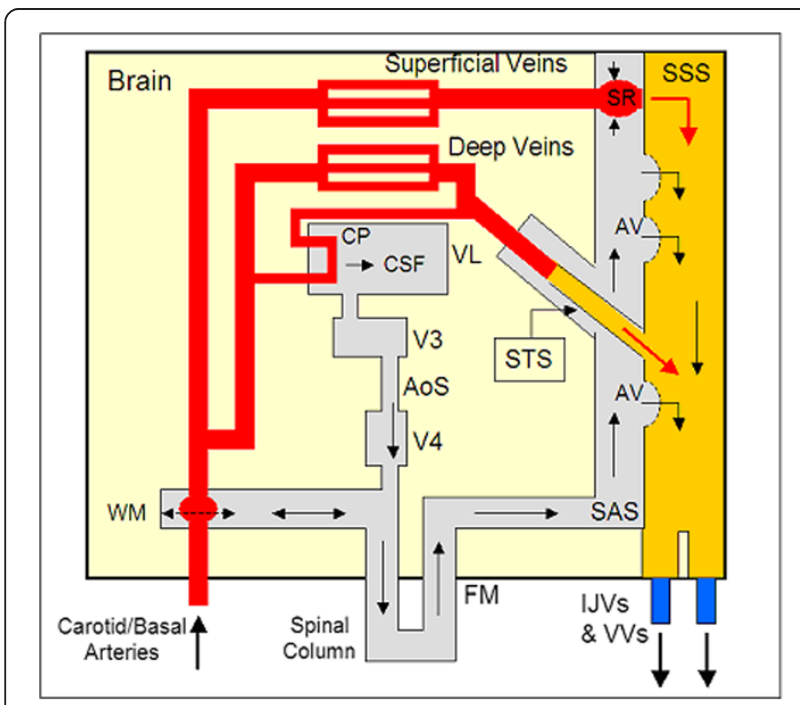

Figure 1 Hydrodynamic model of the brain, showing the interactions between the arterial and venous blood flows and the cerebrospinal fluid (CSF). SSS, superior sagittal sinus; STS, straight sinus; SAS, sub-arachnoid space; AV, arachnoid villi; $C P$, choroid plexus; FM, foramen magnum; WM, windkessel mechanism; SR, Starling resistor; VL, lateral ventricle; V3, third ventricle; V4, fourth ventricle; AoS, aqueduct of Sylvius; IJV, internal jugular vein; W, vertebral veins. flow of blood through the capillary bed [5]. The energy from the arterial pulse is transferred to the CSF, which pulses backwards and forwards across the foramen magnum. The blood flow through the cerebral capillary bed is normally smooth and free from a pulse, but by the time it reaches the venous sinuses, it once again exhibits pulsatile characteristics $[3,169]$. This suggests that energy transferred from the arterial pulse to the CSF is in turn transferred back to the venous-discharge flow.

The various pulses associated with the intracranial hydrodynamic system are illustrated in Figure 2, which shows the transient flow rates of the arterial, venous, and CSF flows in and out of the cranium in a healthy individual [169]. From this, it can be seen that the system is driven by the arterial pulse, which, as it enters the cranium, greatly increases the volume of blood in the pial arteries during systole [1]. Peak CSF flow through the foramen magnum occurs shortly after the arterial peak, which is in turn followed in late systole by a peak in the venous blood flow leaving the cranium. This movement reflects the transfer of kinetic energy from the arterial to the venous pulse via the CSF system. By comparison, the aqueductal CSF pulse, which is not well understood, is much smaller than, and out of phase with, the cervical CSF pulse. In theory, according to the Monro-Kellie doctrine, at any point in time, the volume of CSF leaving the cranium should be equal to the volume difference between the arterial blood entering the cranium and the venous blood leaving it [170]. In reality, however, the Monro-Kellie doctrine is only approximately true [170], and compliance within the intracranial space, together with inertial forces associated with the CSF fluid column, ensure that small transient imbalances occur between the fluid volumes entering and leaving the cranium.

Close inspection of Figure 2 reveals an interesting and poorly understood phenomenon. During diastole, when the excess arterial blood stored by the windkessel mechanism is discharged back into the cerebral vascular bed, the venous blood-flow rate leaving the cranium actually decreases. This implies that during this period, the volume of venous blood in the cranium must be steadily increasing, only to be ejected during systole. Although the physiology associated with this mechanism is not well understood, it seems likely that much of this blood is stored during diastole in the cortical bridging veins that transverse the SAS. Discharge from these veins is controlled by regulatory sphincters $[158,159]$. Constriction of these sphincters results in an increase in the transmural pressure of the bridging veins, causing them to engorge and 'puff out', before periodically discharging into the SSS. Thus, these sphincters, in effect, create Starling resistors, whose characteristics are wholly governed by the respective venous and CSF pressures. Under normal circumstances, this Starling resistor interacts 


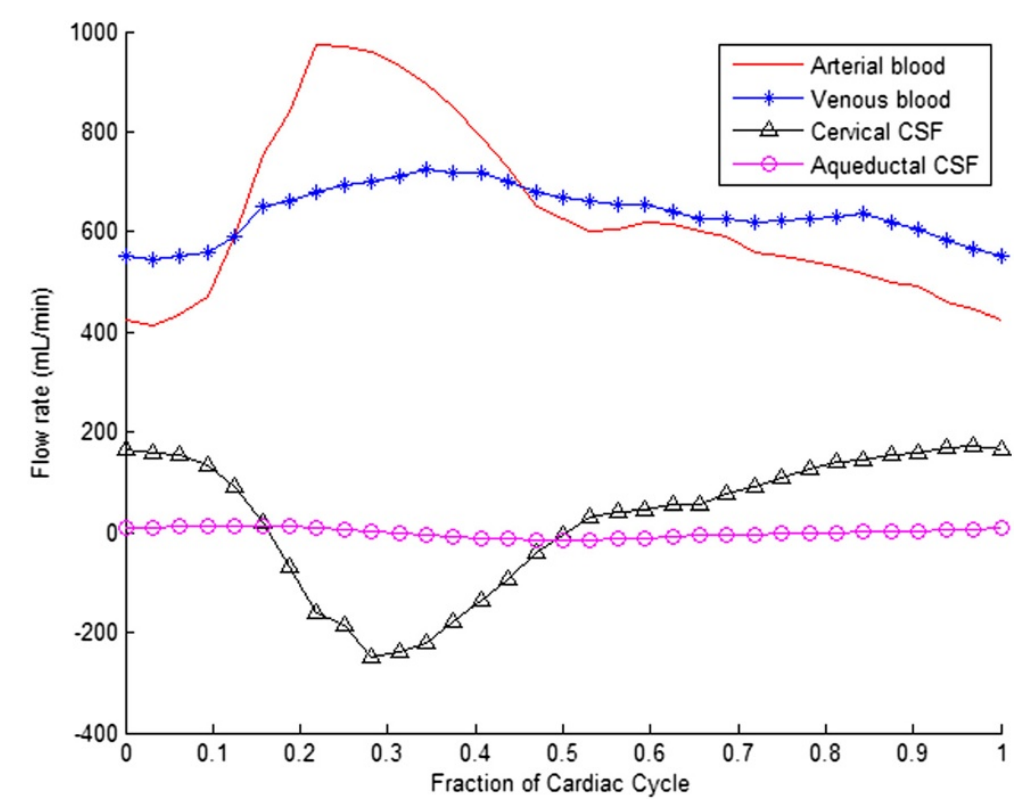

Figure 2 Transient intracranial blood and cerebrospinal fluid (CSF) flow rates over the cardiac cycle in a healthy individual. The figure is based on data published by Ambark et al. [169].

with the CSF pulse in such a way as to ensure the correct flow of blood into the SSS. However, if the venous pressure in the SSS should increase, due to partial occlusion of the cerebral-drainage pathways, then this would change the functional compliance of both the AV and the cortical bridging veins $[2,102,115,116]$. Under normal circumstances, the compliant AV dampen the systolic CSF pressure wave as the wave travels along the SAS, thus reducing the pressure that it exerts on the cortical bridging veins. Venous hypertension in the dural sinuses is therefore likely to reduce the time duration between arterial initiation of the CSF pulse and impingement of that pulse on the cortical bridging veins. Furthermore, it is likely to increase the intensity of the CSF pressure wave impinging on the bridging veins, so that the venous blood is expelled more rapidly into the SSS. Consequently, a reduction in the time duration between the arterial and venous peaks would be expected, which is exactly what Bateman found in patients with NPH $[2,102]$. However, the fluid mechanics associated with this mechanism are complex and it is difficult to predict how the system would behave under different circumstances. For example, if the hydraulic resistance of the cerebral-venous drainage system is greatly increased, as Beggs et al. [64] reported in patients with MS, then rapid discharging of the contents of the cortical veins might lead to a transient increase in pressure in the SSS. How this would behave in practice is a matter of conjecture. It might result in a complex reverse-pressure wave traveling down the cortical veins, as Bateman observed in an individual with leukoaraiosis [3], or alternatively, it could result in venous reflux traveling up the straight sinus, as has been suggested by Schelling [46].

Although the precise behavior of the intracranial hydrodynamic system under conditions of venous hypertension is unknown, there is evidence that occlusion of the venous-drainage pathways causes blood to accumulate within the cranium. In an experiment involving healthy subjects, Kitano et al. [171] showed that compression of the IJVs could result in an increase in intracranial blood volume of 5 to 20\%. Frydrychowski et al. [1] also performed bilateral compression of the IJVs on healthy individuals, and found that it caused a reduction in the width of the SAS, a finding consistent with increased CBV. Furthermore, these authors found that during compression of the IJVs, the pulsatility of the pial arteries traversing the SAS increased by $107 \%$. This suggests that occlusion of the venous-drainage pathways reduces compliance of the intracranial space, impairing the windkessel mechanism, with the result that the blood entering the cerebral microvasculature becomes more pulsatile. Frydrychowski et al. [1] concluded that this mechanism potentially linked jugular-outflow insufficiency with arterial small-vessel cerebral disease. Their work seems to corroborate that of Bateman [5], who found vascular dementia to be associated with greatly increased pulsatility in both the basal venous and straight sinus flows.

\section{Chronic cerebrospinal venous insufficiency}

In 2009, Zamboni et al. published a paper [7] linking a vascular syndrome, CCSVI, with MS. CCSVI is characterized by restricted venous outflow from the brain 
$[8,64]$ due to occlusions, which can take several forms, including the presence of intra-luminal septa, membranes, and immobile valves, as well as segmentary hypoplasia of the veins [172]. CCSVI has proven to be a highly contentious issue $[173,174]$, with a number researchers doubting its validity as a physiological phenomenon [173,175-179]. Notwithstanding this, biomechanically, CCSVI will tend to increase the venous pressure in the dural sinuses, which hypothetically could alter the dynamics of the intracranial CSF system and potentially influence CBF.

The results obtained by researchers for CCSVI have been very mixed. For example, some researchers found CCSVI-like venous anomalies to be strongly associated with MS [7,63,180-186], whereas others found no significant difference between the venous characteristics of healthy controls and patients with MS [173,176,187-190]. Furthermore, CCSVI-like abnormalities are not exclusive to MS, and have been found in lesser numbers in healthy controls [74,180,191] and in those with other neurological diseases [180]. However, a recent meta-analysis of the published evidence showed a positive association between CCSVI and MS, although poor reporting and marked heterogeneity between studies precluded any definitive conclusions [192].

One possible explanation for the discrepancies between studies is the echo color Doppler sonography (ECDS) frequently used to diagnose CCSVI. The floppiness of the vessels involved and the variability of the venous vasculature can lead to erroneous results if ECDS is not undertaken correctly [193-195]. In an attempt to avoid these difficulties, Zamboni et al. [8] developed a non-invasive strain-gauge cervical plethysmography technique for characterizing cerebral-venous drainage in patients with MS. In a blinded study involving healthy controls and patients with MS diagnosed with CCSVI, it was found that the hydraulic resistance of the extracranial venous system was on average $63.5 \%$ greater in those diagnosed with CCSVI compared with controls $(P<0.001)$ [64]. This corroborates the work of Monti et al. [196], who found reduced cerebral-venous outflow in the upright position to be strongly associated $(P<0.0001)$ with MS.

\section{Chronic cerebrospinal venous insufficiency and cerebrospinal fluid flow}

Previous work $[8,64,196]$ strongly suggests that people diagnosed with CCSVI exhibit reduced cerebral-venous outflow, which in some unknown way, is linked to MS. So if CCSVI is a real phenomenon, what role might it play in pathophysiology of MS? Is it a symptom, or part of the etiology? Although it is not currently possible to definitively answer these questions, it is possible, by considering the effects that occlusion of the IJVs might have on the cerebral hydrodynamic system, to gain insights into what might be happening.

Figure 1 describes the principal fluid pathways and interactions that occur within the cranium, and is therefore useful as a tool with which to interpret cerebral hydrodynamic behavior. In fluid mechanics, the flow through any pipe or vessel is governed by the following equation, which is analogous to Ohm's law in electrical engineering:

$$
Q=\frac{\Delta P}{R}
$$

where $Q$ is the fluid flow rate $(\mathrm{ml} / \mathrm{min}), R$ is the hydraulic resistance $(\mathrm{mmHg} . \mathrm{min} / \mathrm{ml})$, and $\Delta P$ represents the pressure drop (pressure gradient; $\mathrm{mmHg}$ ) between the two ends of the vessel. By applying equation 1 to the intracranial system in Figure 1, it is possible to make predictions as to how the system would behave if the IJVs become occluded.

One common feature of CCSVI is stenosis of one or both of the IJVs $[7,197]$, which will tend to increase the hydraulic resistance of these pathways [64]. According to equation 1 , any increase in the resistance due to partial occlusion of the IJVs will result in the two phenomena illustrated in Figure 3. Firstly, this increase in resistance will tend to reduce the flow rate of blood through the IJVs, and secondly, it will increase the pressure gradient through the vessel. Consequently, although hypoperfusion will occur, hypertension will also occur above the obstruction, as is evident by the distension of the IJV frequently seen in patients with CCSVI $[165,197]$. This increase in venous pressure will be transmitted up the vessels into the SSS, which has been shown in patients who exhibit thrombosis of the transverse sinuses [198,199]. Consequently, the increase in blood pressure in the SSS is likely to be the same order of magnitude as that in the IJV; that is, about 2.21 $\mathrm{mmHg}$, according to measurements made by Zamboni et al. [165].

From Figure 1 it can be seen that the SSS acts as a collecting vessel for CSF from the SAS. The CSF bulk flow from the choroid plexus to the SSS via the AV, which in healthy individuals is around 3.3 to $5.5 \mathrm{~mm}^{3}$ / beat (assuming 70 beats $/ \mathrm{min}$ ) [76], is very susceptible to changes in pressure [75]. In normal healthy individuals, the hydraulic resistance of the SAS is very low in comparison with the $\mathrm{AV}$, which means that the outflow of CSF from the SAS to the SSS is almost entirely determined by the AV [76]. These open up when the pressure difference between the SAS and SSS is approximately $5 \mathrm{mmHg}$ [75], allowing free absorption of CSF into the venous blood, a process that has been shown to be linear, with an average rate of $0.1031 \mathrm{ml} / \mathrm{min} / \mathrm{mmHg}$ 


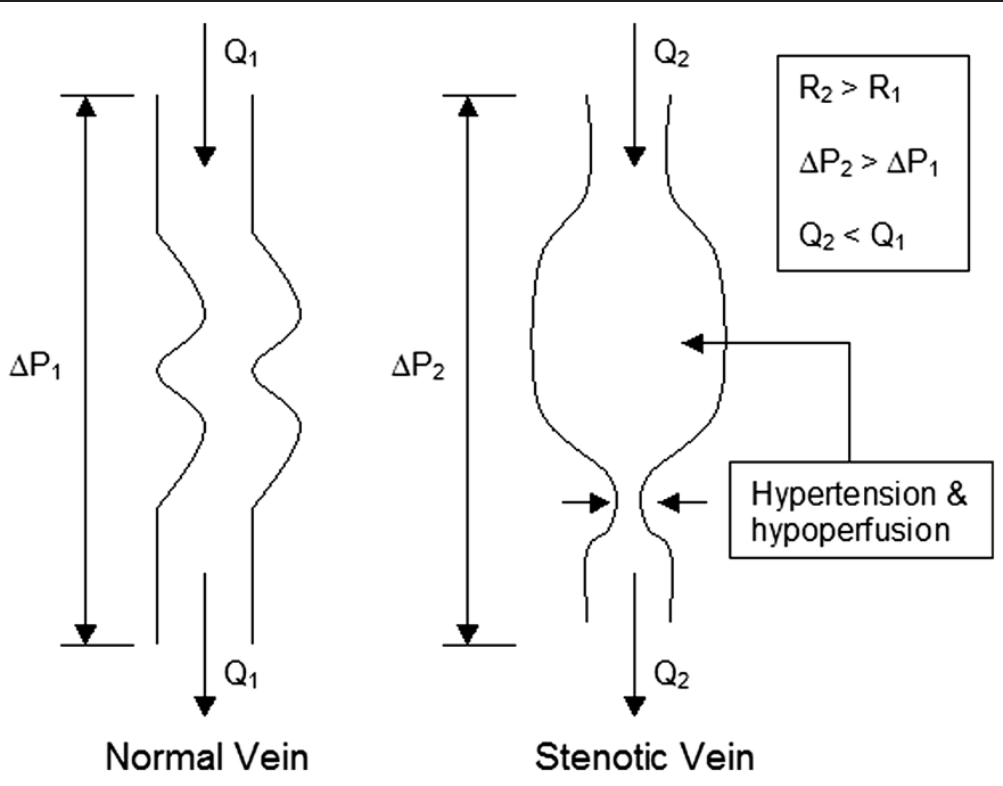

Figure 3 Effect of stenosis on a vein. $Q_{1}$, blood-flow rate through normal vein; $Q_{2}$, blood-flow rate through stenotic vein; $R_{1}$, hydraulic resistance of normal vein; $R_{2}$, hydraulic resistance of stenotic vein; $\Delta P_{1}$, pressure drop through normal vein; and $\Delta P_{2}$, pressure drop through stenotic vein.

$\left(0.0076 \mathrm{ml} / \mathrm{min} / \mathrm{mm} \mathrm{H}_{2} 0\right)$ [75]. Consequently, an increase of $2.21 \mathrm{mmHg}$ in the SSS pressure would equate to a reduction in CSF bulk flow of about $3.26 \mathrm{~mm}^{3} /$ beat (assuming 70 beats $/ \mathrm{min}$ ), which is close to the mean value of $3.4 \mathrm{~mm}^{3}$ /beat reported by Magnano et al. [77] for reduction in CSF bulk flow in patients with MS compared with healthy controls, but somewhat lower than the mean difference of $11.86 \mathrm{~mm}^{3}$ /beat reported by Zamboni et al. [4]. Collectively, these findings support the opinion that venous hypertension in the dural sinuses is a feature of CCSVI.

\section{Chronic cerebrospinal venous insufficiency and cerebral blood flow}

It is possible to gain an insight into the nature of the hemodynamic changes associated with MS, by undertaking simple hydrodynamic analysis of composite data published by Varga et al. [20]. These data are presented

Table 1 Published blood-flow data in the periventricular white matter for healthy controls and patients with relapsing-remitting multiple sclerosis (RR MS) [20]

\begin{tabular}{|c|c|c|c|}
\hline Source & Parameter & $\begin{array}{c}\text { Healthy controls, } \\
\text { mean } \pm S D\end{array}$ & $\begin{array}{c}\text { Patients with } \\
\text { RR MS, } \\
\text { mean } \pm \text { SD }\end{array}$ \\
\hline \multirow{3}{*}{$\begin{array}{l}\text { Varga et al., } \\
2009 \text { [20] }\end{array}$} & $\mathrm{CBF}, \mathrm{ml} / 100 \mathrm{~g} / \mathrm{min}$ & $39.73 \pm 5.0$ & $33.53 \pm 6.10$ \\
\hline & CBV, $\mathrm{ml} / 100 \mathrm{~g}$ & $2.62 \pm 0.60$ & $2.40 \pm 0.40$ \\
\hline & $\mathrm{MTT}, \mathrm{s}$ & $3.94 \pm 0.70$ & $4.33 \pm 0.50$ \\
\hline
\end{tabular}

Abbreviations: $C B F$, Cerebral blood flow; $C B V$, Cerebral blood volume; $M T T$, Mean transit time. in Table 1, and represent measured blood flow in the periventricular WM.

The data in Table 1 complies with the general relationship:

$$
C B F=\frac{C B V}{M T T}
$$

From the data it can be seen that in patients with MS, there is a general reduction in the volume of the vascular bed, which, if approximated to a series of parallel round tubes, equates to a mean reduction in crosssectional area of the vessels of about $8.4 \%$ in patients with MS. According to Poiseuille's Law:

$$
R \propto \frac{1}{r^{4}}
$$

where $\mathrm{R}$ is the hydraulic resistance of the vessel ( $\mathrm{mmHg}$. $\mathrm{min} / \mathrm{ml}$ ) and $\mathrm{r}$ is the radius of the vessel $(\mathrm{mm})$, it can be calculated that the $8.4 \%$ reduction in average crosssectional area equates to an approximately $19.3 \%$ increase in hydraulic resistance. Given that the blood-flow rate is directly proportional to the hydraulic resistance, this means that the reduction in CBV seen in patients with MS, is more than enough to account for the $15.6 \%$ reduction in CBF reported by Varga et al.. According to equation 1, hypertension in the dural sinuses would tend to reduce the pressure gradient pushing the blood through the cerebral veins, which in turn would tend to inhibit blood flow. However, when we consider that the CPP is normally in the region of 70 to $90 \mathrm{mmHg}$, it is unlikely that venous hypertension of less than $5 \mathrm{mmHg}$, 
such as that associated with CCSVI, could account for the large reduction in WM CBF reported in patients with MS [18-21]. Hence, this suggests that the reduction in CBF in patients with MS is probably due to morphological changes in the cerebral vascular bed, rather than a straightforward reduction in perfusion pressure arising from raised pressure in the venous sinuses. However, this does not preclude the possibility that the reduction in CBF may also be due to changes in behavior of the Starling resistor associated with the cortical bridging veins.

Although the above analysis is somewhat simplistic, it does illustrate that cerebral vascular volumetric changes alone appear capable of accounting for the reduction in CBF in the periventricular NAWM in patients with MS. In addition, this finding mirrors those of researchers investigating: 1) reduced CBF [23,83,90,91]; and 2) WM morphological changes around the periventricular veins $[13,14,22,23]$, in patients with leukoaraiosis. Although the above analysis assumes an overall reduction in CBV in patients with MS, this of course does not necessarily imply that all the vessels in the WM have uniformly narrowed, and the results reported by Putnam and Adler [6] regarding periventricular lesions in individuals with MS would suggest otherwise. However, in order to achieve an $8.4 \%$ overall reduction in CBV, systemic changes must be occurring in the WM vascular bed, rather than simply occlusions appearing at specific focal points. The finding by Varga et al. [20] of a 10\% increase in MTT in patients with MS closely mirrors that of Mancini et al. [74], who reported an $8 \%$ increase in MTT. These results strongly suggest that the hydraulic resistance of the whole intracranial vascular circuit is significantly increased in patients with MS. Indeed, it may be the case that some vessels have disappeared completely, as reported by Zivadinov et al. [9], which would inevitably increase the hydraulic resistance of the cerebral vascular circuit.

Further evidence suggesting that occlusion of the cerebral-venous drainage pathways might not be responsible for reduced CBF in patients with MS comes from Moyer et al. [200], who compressed the jugular veins of patients with heart failure; Chai et al. [201], who performed jugular vein ligation in a swine model; and Bateman [202], who investigated idiopathic intracranial hypertension associated with venous outflow stenosis. All these researchers found occlusion of the venous pathways to be associated with CBF rates that were higher than normal. This counterintuitive finding could only be physically possible if the hydraulic resistance of the cerebral blood vessels were greatly reduced, suggesting that obstruction of the venous-drainage pathways results in vasodilatation and increased CBV. However, studies have found CBV to be reduced by 8.4 to $13.6 \%$ in patients with MS compared with healthy controls [18-20], suggesting that hyperemia may not in fact be a feature of this disease. Interestingly, Chai et al. [201] reported that cerebral oxygen consumption was significantly increased when venous ligation was applied, which suggests that venous hypertension might alter the metabolism of the brain. Although the effects of venous hypertension on cerebral metabolism are largely unexplored, it is known that the brain regulates blood flow according to its metabolic needs. Consequently, it is difficult to know the extent to which reduced CBF is initiated by venous hypertension or endothelial morphological changes, as opposed to downregulation of the metabolic activity of the brain.

\section{Conclusions}

Although much research work has been undertaken into the contribution of venous abnormalities to various neurological conditions, there has generally been a lack of any hydrodynamic analysis to interpret the data collected. Without such analysis, it is possible to misinterpret results and come to potentially erroneous conclusions [174]. In the analytical review presented here, we have sought to redress this issue, and have been able to show that CCSVI-like anomalies in the extracranial venous system are unlikely to account for the reduction in CBF reported in patients with MS. Rather, our analysis suggests that other pathophysiological mechanisms must be a work, which are increasing the hydraulic resistance of the cerebral vascular bed in patients with MS. Similarly, changes in the cerebral microvasculature seem to be responsible for reduced CBF in leukoaraiosis. CBF in the WM is markedly reduced in both MS and leukoaraiosis, and in both conditions, lesions exhibit signs of ischemia, although to a lesser extent in the case of MS. Under conditions of hypoperfusion, the laws governing mass transfer indicate that the cerebral veins are more likely to be affected by hypoxic stress compared with the arterioles and capillaries, and this might, in part, explain why the plaques in MS tend to be perivenular in nature. With respect to this, the hydrodynamic properties of the periventricular veins appear to make these vessels particularly vulnerable to plaque formation.

Venous hypertension in the dural sinuses seems to be associated with marked changes in intracranial compliance. There is sound theoretical reason to believe that this will alter the dynamics of the intracranial CSF system, which in turn may affect the finely tuned intracranial windkessel mechanism. With respect to this, MS and NPH appear to share some similar characteristics. In particular, both conditions seem to be characterized by increased CSF pulsatility in the AoS.

Despite conflicting studies, there is increasing evidence that CCSVI is a real physiological phenomenon, and that it is in some way associated with MS. The evidence from 
CSF-related studies in patients with MS, and the hydrodynamic analysis presented here, suggests that CCSVI causes venous hypertension in the dural sinuses. However, the role that CCSVI might play in the pathophysiology of MS remains unclear, and more work is urgently needed to understand the clinical relevance of this condition.

\section{Abbreviations}

ADC: Apparent diffusion coefficient; AoS: Aqueduct of Sylvius; AV: Arachnoid villi; AVD: Arteriovenous delay; BBB: Blood-brain barrier; CBF: Cerebral blood flow; CBV: Cerebral blood volume; CCSVI: Chronic cerebrospinal venous insufficiency; CNS: Central nervous system; CPP: Cerebral perfusion pressure; CSF: Cerebrospinal fluid; DVA: Developmental venous anomaly; ECDS: Echo color doppler sonography; GM: Grey matter; HIF: Hypoxia-inducible factor; ICP: Intracranial pressure; IJV: Internal jugular veins; JVR: Jugular venous reflux; MRI: Magnetic resonance imaging; MS: Multiple sclerosis; MTT: Mean transit time; NAWM: Normal-appearing white matter; NPH: Normal-pressure hydrocephalus; PVC: Periventricular venous collagenosis; RR:

Relapsing-remitting; SAS: Sub-arachnoid space; SSS: Superior sagittal sinus; SWI: Susceptibility-weighted imaging; WV: Venous vasculature visibility; WM: White matter.

\section{Competing interests}

The author declares no conflicts of interest.

\section{Authors' contributions}

The study was conceived and undertaken by CBB, who also wrote the manuscript.

\section{Acknowledgements}

I would like to thank Robert Zivadinov for his helpful insights regarding the formation of grey matter lesions in patients with MS. The study was self-funded.

Received: 2 January 2013 Accepted: 20 February 2013

Published: 31 May 2013

\section{References}

1. Frydrychowski AF, Winklewski PJ, Guminski W: Influence of acute jugular vein compression on the cerebral blood flow velocity, pial artery pulsation and width of subarachnoid space in humans. PLoS One 2012, 7:e48245.

2. Bateman GA: The pathophysiology of idiopathic normal pressure hydrocephalus: cerebral ischemia or altered venous hemodynamics? AJNR Am J Neuroradiol 2008, 29:198-203.

3. Bateman GA: Pulse-wave encephalopathy: a comparative study of the hydrodynamics of leukoaraiosis and normal-pressure hydrocephalus. Neuroradiology 2002, 44:740-748.

4. Zamboni P, Menegatti E, Weinstock-Guttman B, Schirda C, Cox JL, Malagoni AM, Hojanacki D, Kennedy C, Carl E, Dwyer MG, Bergsland N, Galeotti R, Hussein S, Bartolomei I, Salvi F, Zivadinov R: The severity of chronic cerebrospinal venous insufficiency in patients with multiple sclerosis is related to altered cerebrospinal fluid dynamics. Funct Neurol 2009, 24:133-138.

5. Bateman GA, Levi CR, Schofield P, Wang Y, Lovett EC: The venous manifestations of pulse wave encephalopathy: windkessel dysfunction in normal aging and senile dementia. Neuroradiology 2008, 50:491-497.

6. Putnam TJ, Adler A: Vascular architecture of the lesions of multiple sclerosis. Arch Neurol Psychiat 1937, 38:1-5.

7. Zamboni P, Galeotti R, Menegatti E, Malagoni AM, Tacconi G, Dall'Ara S, Bartolomei I, Salvi F: Chronic cerebrospinal venous insufficiency in patients with multiple sclerosis. J Neurol Neurosurg Psychiatry 2009, 80:392-399.

8. Zamboni P, Menegatti E, Conforti P, Shepherd S, Tessari M, Beggs C: Assessment of cerebral venous return by a novel plethysmography method. J Vasc Surg 2012, 56:677-685.

9. Zivadinov R, Poloni GU, Marr K, Schirda CV, Magnano CR, Carl E, Bergsland N, Hojnacki D, Kennedy C, Beggs CB, Dwyer MG, Weinstock-Guttman B:
Decreased brain venous vasculature visibility on susceptibility-weighted imaging venography in patients with multiple sclerosis is related to chronic cerebrospinal venous insufficiency. BMC Neurol 2011, 11:128.

10. Dawson JW: The histology of disseminated sclerosis. Trans Roy Soc Edinb 1916, 50:517.

11. Putnam TJ: Evidences of vascular occlusion in multiple sclerosis and encephalomyelitis. Arch Neurol Psychiatry 1937, 6:1298-1321.

12. Brown WR, Moody DM, Thore CR, Challa VR, Anstrom JA: Vascular dementia in leukoaraiosis may be a consequence of capillary loss not only in the lesions, but in normal-appearing white matter and cortex as well. J Neurol Sci 2007, 257:62-66.

13. Moody DM, Brown WR, Challa VR, Anderson RL: Periventricular venous collagenosis: association with leukoaraiosis. Radiology 1995, 194:469-476.

14. Brown WR, Moody DM, Thore CR, Anstrom JA, Challa VR: Microvascular changes in the white mater in dementia. J Neurol Sci 2009, 283:28-31.

15. Chung $\mathrm{CP}, \mathrm{Hu} \mathrm{HH}$ : Pathogenesis of leukoaraiosis: role of jugular venous reflux. Med Hypotheses 2010, 75:85-90.

16. Chung CP, Wang PN, Wu YH, Tsao YC, Sheng WY, Lin KN, Lin SJ, Hu HH: More severe white matter changes in the elderly with jugular venous reflux. Ann Neurol 2011, 69:553-559.

17. Bateman GA: Pulse wave encephalopathy: a spectrum hypothesis incorporating Alzheimer's disease, vascular dementia and normal pressure hydrocephalus. Med Hypotheses 2004, 62:182-187.

18. Law M, Saindane AM, Ge Y, Babb JS, Johnson G, Mannon LJ, Herbert J Grossman Rl: Microvascular abnormality in relapsing-remitting multiple sclerosis: perfusion MR imaging findings in normal-appearing white matter. Radiology 2004, 231:645-652.

19. Ge Y, Law M, Johnson G, Herbert J, Babb JS, Mannon LJ, Grossman Rl: Dynamic susceptibility contrast perfusion MR imaging of multiple sclerosis lesions: characterizing hemodynamic impairment and inflammatory activity. AJNR Am J Neuroradiol 2005, 26:1539-1547.

20. Varga AW, Johnson G, Babb JS, Herbert J, Grossman RI, Inglese M: White matter hemodynamic abnormalities precede sub-cortical gray matter changes in multiple sclerosis. J Neurol Sci 2009, 282:28-33.

21. Adhya S, Johnson G, Herbert J, Jaggi H, Babb JS, Grossman Rl, Inglese M: Pattern of hemodynamic impairment in multiple sclerosis: dynamic susceptibility contrast perfusion MR imaging at 3.0 T. Neurolmage 2006, 33:1029-1035.

22. Moody DM, Brown WR, Challa VR, Ghazi-Birry HS, Reboussin DM: Cerebral microvascular alterations in aging, leukoaraiosis, and Alzheimer's disease. Ann N Y Acad Sci 1997, 826:103-116.

23. Brown WR, Thore CR: Review: cerebral microvascular pathology in ageing and neurodegeneration. Neuropathol Appl Neurobiol 2011, 37:56-74.

24. Dalton CM, Brex PA, Jenkins R, Fox NC, Miszkiel KA, Crum WR, O'Riordan Jl, Plant GT, Thompson AJ, Miller DH: Progressive ventricular enlargement in patients with clinically isolated syndromes is associated with the early development of multiple sclerosis. J Neurol Neurosurg Psychiatry 2002, 73:141-147.

25. Dalton CM, Miszkiel KA, O'Connor PW, Plant GT, Rice GP, Miller DH: Ventricular enlargement in MS: one-year change at various stages of disease. Neurology 2006, 66:693-698.

26. Bradley WG: Normal pressure hydrocephalus: new concepts on etiology and diagnosis. AJNR Am J Neuroradiol 2000, 21:1586-1590.

27. Kitagaki H, Mori E, Ishii K, Yamaji S, Hirono N, Imamura T: CSF spaces in idiopathic normal pressure hydrocephalus: morphology and volumetry. AJNR Am J Neuroradiol 1998, 19:1277-1284.

28. Benedetti MG, Piperno R, Simoncini L, Bonato P, Tonini A, Giannini S: Gait abnormalities in minimally impaired multiple sclerosis patients. Mult Scler 1999, 5:363-368.

29. Briley DP, Wasay M, Sergent $S$, Thomas $S$ : Cerebral white matter changes (leukoaraiosis), stroke, and gait disturbance. J Am Geriatr Soc 1997, 45:1434-1438

30. Sakakibara R, Hattori T, Uchiyama T, Yamanishi T: Urinary function in elderly people with and without leukoaraiosis: relation to cognitive and gait function. J Neurol Neurosurg Psychiatry 1999, 67:658-660.

31. Mori E: Gait disturbance in idiopathic normal pressure hydrocephalus. Brain Nerve 2008, 60:219-224.

32. Chiaravalloti ND, DeLuca J: Cognitive impairment in multiple sclerosis. Lancet Neurol 2008, 7:1139-1151.

33. Saito M, Nishio Y, Kanno S, Uchiyama M, Hayashi A, Takagi M, Kikuchi H, Yamasaki H, Shimomura T, lizuka O, Mori E: Cognitive profile of 
idiopathic normal pressure hydrocephalus. Dement Geriatr Cogn Dis Extra 2011, 1:202-211.

34. Fowler CJ, Panicker JN, Drake M, Harris C, Harrison SC, Kirby M, Lucas M, Macleod N, Mangnall J, North A, Porter B, Reid S, Russell N, Watkiss K, Wells M: A UK consensus on the management of the bladder in multiple sclerosis. J Neurol Neurosurg Psychiatry 2009, 80:470-477.

35. Sakakibara R, Kanda T, Sekido T, Uchiyama T, Awa Y, Ito T, Liu Z, Yamamoto T, Yamanishi T, Yuasa T, Shirai K, Hattori T: Mechanism of bladder dysfunction in idiopathic normal pressure hydrocephalus. Neurourol Urodyn 2008, 27:507-510.

36. Ge Y, Grossman RI, Udupa JK, Babb JS, Nyul LG, Kolson DL: Brain atrophy in relapsing-remitting multiple sclerosis: fractional volumetric analysis of gray matter and white matter. Radiology 2001, 220:606-610.

37. Ge Y, Grossman Rl, Udupa JK, Wei L, Mannon LJ, Polansky M, Kolson DL: Brain atrophy in relapsing-remitting multiple sclerosis and secondary progressive multiple sclerosis: longitudinal quantitative analysis. Radiology 2000, 214:665-670.

38. Bradley WG Jr, Whittemore AR, Kortman KE, Watanabe AS, Homyak M, Teresi LM, Davis SJ: Marked cerebrospinal fluid void: indicator of successful shunt in patients with suspected normal-pressure hydrocephalus. Radiology 1991, 178:459-466.

39. Bradley WG: Cerebrospinal fluid dynamics and shunt responsiveness in patients with normal-pressure hydrocephalus. Mayo Clin Proc 2002, 77:507-508

40. O'Sullivan M, Morris RG, Huckstep B, Jones DK, Williams SC, Markus HS: Diffusion tensor MRI correlates with executive dysfunction in patients with ischaemic leukoaraiosis. J Neurol Neurosurg Psychiatry 2004, 75:441-447.

41. Bruck $W$ : The pathology of multiple sclerosis is the result of focal inflammatory demyelination with axonal damage. J Neurol 2005, 252:v3-v9.

42. Fernandez M, Giuliani A, Pirondi S, D'Intino G, Giardino L, Aloe L, Levi-Montalcini R, Calza L: Thyroid hormone administration enhances remyelination in chronic demyelinating inflammatory disease. Proc Natl Acad Sci U S A 2004, 101:16363-16368.

43. Sloane JA, Batt C, Ma Y, Harris ZM, Trapp B, Vartanian T: Hyaluronan blocks oligodendrocyte progenitor maturation and remyelination through TLR2. Proc Natl Acad Sci U S A 2010, 107:11555-11560.

44. Schwartz GL, Fornage M, Mosley T, Turner ST: Treatment of leukoaraiosis. Curr Treat Options Cardiovasc Med 2005, 7:173-177.

45. Fog T: On the vessel-plaque relations in the brain in multiple sclerosis. Acta Neurol Scand Suppl 1963, 39:258-262.

46. Schelling F: Damaging venous reflux into the skull or spine: relevance to multiple sclerosis. Med Hypotheses 1986, 21:141-148.

47. Talbert DG: Raised venous pressure as a factor in multiple sclerosis. Med Hypotheses 2008, 70:1112-1117.

48. Adams CW, Abdulla YH, Torres EM, Poston RN: Periventricular lesions in multiple sclerosis: their perivenous origin and relationship to granular ependymitis. Neuropathol Appl Neurobiol 1987, 13:141-152.

49. Adams CW: Perivascular iron deposition and other vascular damage in multiple sclerosis. J Neurol Neurosurg Psychiatry 1988, 51:260-265.

50. Kidd D, Barkhof F, McConnell R, Algra PR, Allen IV, Revesz T: Cortical lesions in multiple sclerosis. Brain 1999, 122:17-26.

51. Kermode AG, Thompson AJ, Tofts P, MacManus DG, Kendall BE, Kingsley DP, Moseley IF, Rudge P, McDonald WI: Breakdown of the blood-brain barrier precedes symptoms and other MRI signs of new lesions in multiple sclerosis. Pathogenetic and clinical implications. Brain 1990, 113:1477-1489

52. Tan IL, van Schijndel RA, Pouwels PJ, van Walderveen MA, Reichenbach JR, Manoliu RA, Barkhof F: MR venography of multiple sclerosis. AJNR Am J Neuroradiol 2000, 21:1039-1042.

53. Tallantyre EC, Dixon JE, Donaldson I, Owens T, Morgan PS, Morris PG, Evangelou N: Ultra-high-field imaging distinguishes MS lesions from asymptomatic white matter lesions. Neurology 2011, 76:534-539.

54. Duvernoy HM, Delon S, Vannson JL: Cortical blood vessels of the human brain. Brain Res Bull 1981, 7:519-579.

55. Gilmore CP, Donaldson I, Bo L, Owens T, Lowe J, Evangelou N: Regional variations in the extent and pattern of grey matter demyelination in multiple sclerosis: a comparison between the cerebral cortex, cerebellar cortex, deep grey matter nuclei and the spinal cord. J Neurol Neurosurg Psychiatry 2009, 80:182-187.
56. Young NP, Weinshenker BG, Parisi JE, Scheithauer B, Giannini C, Roemer SF, Thomsen KM, Mandrekar JN, Erickson BJ, Lucchinetti CF: Perivenous demyelination: association with clinically defined acute disseminated encephalomyelitis and comparison with pathologically confirmed multiple sclerosis. Brain 2010, 133:333-348.

57. Pitt D, Boster A, Pei W, Wohleb E, Jasne A, Zachariah CR, Rammohan K Knopp MV, Schmalbrock P: Imaging cortical lesions in multiple sclerosis with ultra-high-field magnetic resonance imaging. Arch Neurol 2010, 67:812-818

58. Sospedra M, Martin R: Immunology of multiple sclerosis. Annu Rev Immunol 2005, 23:683-747

59. Martin R, McFarland HF, McFarlin DE: Immunological aspects of demyelinating diseases. Annu Rev Immunol 1992, 10:153-187.

60. D'Haeseleer M, Cambron M, Vanopdenbosch L, De Keyser J: Vascular aspects of multiple sclerosis. Lancet Neurol 2011, 10:657-666.

61. De Keyser J, Steen C, Mostert JP, Koch MW: Hypoperfusion of the cerebral white matter in multiple sclerosis: possible mechanisms and pathophysiological significance. J Cereb Blood Flow Metab 2008, 28:1645-1651.

62. Lassmann H: Hypoxia-like tissue injury as a component of multiple sclerosis lesions. J Neuro/ Sci 2003, 206:187-191.

63. Al-Omari MH, Rousan LA: Internal jugular vein morphology and hemodynamics in patients with multiple sclerosis. Int Angiol 2010, 29:115-120.

64. Beggs C, Shepherd S, Zamboni P: Cerebral venous outflow resistance and interpretation of cervical plethysmography data with respect to the diagnosis of chronic cerebrospinal venous insufficiency. Phlebology 2012. Epub ahead of print.

65. Zamboni P, Menegatti E, Weinstock-Guttman B, Dwyer MG, Schirda CV Malagoni AM, Hojnacki D, Kennedy C, Carl E, Bergsland N, Magnano C, Bartolomei I, Salvi F, Zivadinov R: Hypoperfusion of brain parenchyma is associated with the severity of chronic cerebrospinal venous insufficiency in patients with multiple sclerosis: a cross-sectional preliminary report. BMC Med 2011, 9:22.

66. Ge Y, Zohrabian VM, Osa EO, Xu J, Jaggi H, Herbert J, Haacke EM, Grossman RI: Diminished visibility of cerebral venous vasculature in multiple sclerosis by susceptibility-weighted imaging at 3.0 Tesla. J Magn Reson Imaging 2009, 29:1190-1194.

67. Beggs CB, Shepherd SJ, Dwyer MG, Polak P, Magnano C, Carl E, Poloni G, Weinstein-Guttman B, Zivadinov R: Sensitivity and specificity of SWI venography for detection of cerebral venous alterations in multiple sclerosis. Neurol Res 2012, 34:793-801.

68. Brooks DJ, Leenders KL, Head G, Marshall J, Legg NJ, Jones T: Studies on regional cerebral oxygen utilisation and cognitive function in multiple sclerosis. J Neurol Neurosurg Psychiatry 1984, 47:1182-1191.

69. Lycke J, Wikkelso C, Bergh AC, Jacobsson L, Andersen O: Regional cerebral blood flow in multiple sclerosis measured by single photon emission tomography with technetium-99m hexamethylpropyleneamine oxime. Eur Neurol 1993, 33:163-167.

70. Sun X, Tanaka M, Kondo S, Okamoto K, Hirai S: Clinical significance of reduced cerebral metabolism in multiple sclerosis: a combined PET and MRI study. Ann Nucl Med 1998, 12:89-94.

71. Swank RL, Roth JG, Woody DC Jr: Cerebral blood flow and red cell delivery in normal subjects and in multiple sclerosis. Neurol Res 1983, 5:37-59.

72. Rashid W, Parkes LM, Ingle GT, Chard DT, Toosy AT, Altmann DR, Symms MR, Tofts PS, Thompson AJ, Miller DH: Abnormalities of cerebral perfusion in multiple sclerosis. J Neurol Neurosurg Psychiatry 2004, 75:1288-1293.

73. Inglese M, Adhya S, Johnson G, Babb JS, Miles L, Jaggi H, Herbert J, Grossman Rl: Perfusion magnetic resonance imaging correlates of neuropsychological impairment in multiple sclerosis. J Cereb Blood Flow Metab 2008, 28:164-171.

74. Mancini M, Morra VB, Di Donato O, Maglio V, Lanzillo R, Liuzzi R, Salvatore E, Brunetti A, laccarino V, Salvatore M: Multiple sclerosis: cerebral circulation time. Radiology 2012, 262:947-955.

75. Cutler RW, Page L, Galicich J, Watters GV: Formation and absorption of cerebrospinal fluid in man. Brain 1968, 91:707-720.

76. Ekstedt J: CSF hydrodynamic studies in man. 2. Normal hydrodynamic variables related to CSF pressure and flow. J Neurol Neurosurg Psychiatry 1978, 41:345-353.

77. Magnano C, Schirda C, Weinstock-Guttman B, Wack DS, Lindzen E, Hojnacki D, Bergsland N, Kennedy C, Belov P, Dwyer MG, Poloni GU, Beggs 
CB, Zivadinov R: Cine cerebrospinal fluid imaging in multiple sclerosis. J Magn Reson Imaging 2012, 36:825-834.

78. Popescu BF, Lucchinetti CF: Meningeal and cortical grey matter pathology in multiple sclerosis. BMC Neuro/ 2012, 12:11.

79. Kutzelnigg A, Lassmann $\mathrm{H}$ : Cortical demyelination in multiple sclerosis: a substrate for cognitive deficits? J Neuro/ Sci 2006, 245:123-126.

80. Helenius J, Soinne L, Salonen O, Kaste M, Tatlisumak T: Leukoaraiosis, ischemic stroke, and normal white matter on diffusion-weighted MRI Stroke 2002, 33:45-50.

81. Ylikoski R, Ylikoski A, Erkinjuntti T, Sulkava R, Raininko R, Tilvis R: White matter changes in healthy elderly persons correlate with attention and speed of mental processing. Arch Neurol 1993, 50:818-824.

82. van Gijn J: Leukoaraiosis and vascular dementia. Neurology 1998, 51:S3-S8.

83. Kawamura J, Meyer JS, Terayama Y, Weathers S: Leukoaraiosis correlates with cerebral hypoperfusion in vascular dementia. Stroke 1991, 22:609-614

84. Inzitari D, Cadelo M, Marranci ML, Pracucci G, Pantoni L: Vascular deaths in elderly neurological patients with leukoaraiosis. J Neurol Neurosurg Psychiatry 1997, 62:177-181.

85. Kawamura J, Meyer JS, Ichijo M, Kobari M, Terayama Y, Weathers S: Correlations of leuko-araiosis with cerebral atrophy and perfusion in elderly normal subjects and demented patients. J Neurol Neurosurg Psychiatry 1993, 56:182-187.

86. Simon J: Ischemia and multiple sclerosis: perfusion MR imaging provides insight into an underexplored pathophysiology. AJNR Am J Neuroradiol 2005, 26:1306-1308.

87. Jack CR Jr, O'Brien PC, Rettman DW, Shiung MM, Xu Y, Muthupillai R, Manduca A, Avula R, Erickson BJ: FLAIR histogram segmentation for measurement of leukoaraiosis volume. J Magn Reson Imaging 2001, 14:668-676.

88. Pantoni L, Garcia JH: Pathogenesis of leukoaraiosis: a review. Stroke 1997 28:652-659.

89. Inzitari D, Mascalchi M, Giordano GP, Marini P, Sita D, Abbamondi AL: Histopathological correlates of leuko-araiosis in patients with ischemic stroke. Eur Neurol 1989, 29:23-26.

90. O'Sullivan M, Lythgoe DJ, Pereira AC, Summers PE, Jarosz JM, Williams SC, Markus HS: Patterns of cerebral blood flow reduction in patients with ischemic leukoaraiosis. Neurology 2002, 59:321-326.

91. Markus HS, Lythgoe DJ, Ostegaard L, O'Sullivan M, Williams SC: Reduced cerebral blood flow in white matter in ischaemic leukoaraiosis demonstrated using quantitative exogenous contrast based perfusion MRI. J Neurol Neurosurg Psychiatry 2000, 69:48-53.

92. Inzitari D, Diaz F, Fox A, Hachinski VC, Steingart A, Lau C, Donald A, Wade J, Mulic $\mathrm{H}$, Merskey $\mathrm{H}$ : Vascular risk factors and leuko-araiosis. Arch Neurol 1987, 44:42-47.

93. Inzitari D, Giordano GP, Ancona AL, Pracucci G, Mascalchi M, Amaducci L: Leukoaraiosis, intracerebral hemorrhage, and arterial hypertension. Stroke 1990, 21:1419-1423

94. Wiszniewska M, Devuyst G, Bogousslavsky J, Ghika J, van Melle G: What is the significance of leukoaraiosis in patients with acute ischemic stroke? Arch Neurol 2000, 57:967-973.

95. Furuta A, Ishii N, Nishihara $Y$, Horie A: Medullary arteries in aging and dementia. Stroke 1991, 22:442-446.

96. Fazekas F, Kleinert R, Offenbacher H, Schmidt R, Kleinert G, Payer F, Radner H, Lechner H: Pathologic correlates of incidental MRI white matter signal hyperintensities. Neurology 1993, 43:1683-1689.

97. van Swieten JC, van den Hout JH, van Ketel BA, Hijdra A, Wokke JH, van Gijn J: Periventricular lesions in the white matter on magnetic resonance imaging in the elderly. A morphometric correlation with arteriolosclerosis and dilated perivascular spaces. Brain 1991, 114:761-774

98. Brown WR, Moody DM, Challa VR, Thore CR, Anstrom JA: Venous collagenosis and arteriolar tortuosity in leukoaraiosis. J Neurol Sci 2002, 203-204:159-163

99. Moody DM, Santamore WP, Bell MA: Does tortuosity in cerebral arterioles impair down-autoregulation in hypertensives and elderly normotensives? A hypothesis and computer model. Clin Neurosurg 1991 37:372-387

100. Thore CR, Anstrom JA, Moody DM, Challa VR, Marion MC, Brown WR: Morphometric analysis of arteriolar tortuosity in human cerebral white matter of preterm, young, and aged subjects. I Neuropathol Exp Neurol 2007, 66:337-345.
101. Chung CP, Lin YJ, Chao AC, Lin SJ, Chen YY, Wang YJ, Hu HH: Jugular venous hemodynamic changes with aging. Ultrasound Med Biol 2010, 36:1776-1782

102. Bateman GA: Vascular compliance in normal pressure hydrocephalus. AJNR Am J Neuroradiol 2000, 21:1574-1585.

103. Bateman GA: Vascular hydraulics associated with idiopathic and secondary intracranial hypertension. AJNR Am J Neuroradiol 2002, 23:1180-1186.

104. Guyton AC, Hall JE: Textbook of Medical Physiology. 10th edition. Philadelphia: Saunders; 2000.

105. Shaaban AM, Duerinckx AJ: Wall shear stress and early atherosclerosis: a review. AJR Am J Roentgenol 2000, 174:1657-1665.

106. Kiefer $M$, Unterberg $A$ : The differential diagnosis and treatment of normal-pressure hydrocephalus. Dtsch Arztebl Int 2012, 109:15-25. quiz 26.

107. Tsunoda A, Mitsuoka H, Bandai H, Endo T, Arai H, Sato K: Intracranial cerebrospinal fluid measurement studies in suspected idiopathic normal pressure hydrocephalus, secondary normal pressure hydrocephalus, and brain atrophy. J Neurol Neurosurg Psychiatry 2002, 73:552-555.

108. Hakim S, Adams RD: The special clinical problem of symptomatic hydrocephalus with normal cerebrospinal fluid pressure. Observations on cerebrospinal fluid hydrodynamics. J Neurol Sci 1965, 2:307-327.

109. Hankey GJ, Wardlaw JM: Clinical Neurology. London: Manson Publishing; 2002.

110. Bateman GA: The reversibility of reduced cortical vein compliance in normal-pressure hydrocephalus following shunt insertion. Neuroradiology 2003, 45:65-70.

111. Egnor M, Zheng L, Rosiello A, Gutman F, Davis R: A model of pulsations in communicating hydrocephalus. Pediatr Neurosurg 2002, 36:281-303.

112. El Sankari S, Gondry-Jouet C, Fichten A, Godefroy O, Serot JM, Deramond H, Meyer ME, Baledent O: Cerebrospinal fluid and blood flow in mild cognitive impairment and Alzheimer's disease: a differential diagnosis from idiopathic normal pressure hydrocephalus. Fluids Barriers CNS 2011, $8: 12$.

113. Miyati T, Mase M, Kasai H, Hara M, Yamada K, Shibamoto $Y$, Soellinger M, Baltes C, Luechinger R: Noninvasive MRI assessment of intracranial compliance in idiopathic normal pressure hydrocephalus. J Magn Reson Imaging 2007, 26:274-278.

114. Mase M, Miyati T, Kasai H, Demura K, Osawa T, Hara M, Shibamoto Y, Yamada K: Noninvasive estimation of intracranial compliance in idiopathic NPH using MRI. Acta Neurochir Supp/ 2008, 102:115-118.

115. Williams $H$ : The venous hypothesis of hydrocephalus. Med Hypotheses 2008, 70:743-747

116. Williams $\mathrm{H}$ : A unifying hypothesis for hydrocephalus, Chiari malformation, syringomyelia, anencephaly and spina bifida. Cerebrospinal Fluid Res 2008, 5:7

117. Rekate HL: A consensus on the classification of hydrocephalus: its utility in the assessment of abnormalities of cerebrospinal fluid dynamics. Childs Nerv Syst 2011, 27:1535-1541.

118. Bradley WG Jr: Idiopathic normal pressure hydrocephalus: new findings and thoughts on etiology. AJNR Am J Neuroradiol 2008, 29:1-3.

119. Nakahara Y, Ogata A, Takase Y, Maeda K, Okamoto H, Matsushima T, Sakata S: Treatment of dural arteriovenous fistula presenting as typical symptoms of hydrocephalus caused by venous congestion: case report. Neurol Med Chir (Tokyo) 2011, 51:229-232.

120. Graff-Radford NR, Rezai K, Godersky JC, Eslinger P, Damasio H, Kirchner PT: Regional cerebral blood flow in normal pressure hydrocephalus. J Neurol Neurosurg Psychiatry 1987, 50:1589-1596.

121. Owler BK, Momjian S, Czosnyka Z, Czosnyka M, Péna A, Harris NG, Smielewski P, Fryer T, Donovan T, Coles J, Carpenter A, Pickard JD: Normal pressure hydrocephalus and cerebral blood flow: a PET study of baseline values. J Cereb Blood Flow Metab 2004, 24:17-23.

122. Momjian S, Owler BK, Czosnyka Z, Czosnyka M, Pena A, Pickard JD: Pattern of white matter regional cerebral blood flow and autoregulation in normal pressure hydrocephalus. Brain 2004, 127:965-972.

123. Larsson A, Bergh AC, Bilting M, Arlig A, Jacobsson L, Stephensen H, Wikkelso $C$ : Regional cerebral blood flow in normal pressure hydrocephalus: diagnostic and prognostic aspects. Eur J Nucl Med 1994, 21:118-123.

124. Tullberg M, Jensen C, Ekholm S, Wikkelso C: Normal pressure hydrocephalus: vascular white matter changes on MR images must not exclude patients from shunt surgery. AJNR Am J Neuroradiol 2001, 22:1665-1673.

125. Luetmer PH, Huston J, Friedman JA, Dixon GR, Petersen RC, Jack CR, McClelland RL, Ebersold MJ: Measurement of cerebrospinal fluid flow at 
the cerebral aqueduct by use of phase-contrast magnetic resonance imaging: technique validation and utility in diagnosing idiopathic normal pressure hydrocephalus. Neurosurgery 2002, 50:534-543. discussion 543-534.

126. Schroth G, Klose U: Cerebrospinal fluid flow. III. Pathological cerebrospinal fluid pulsations. Neuroradiology 1992, 35:16-24.

127. Gideon P, Stahlberg F, Thomsen C, Gjerris F, Sorensen PS, Henriksen O: Cerebrospinal fluid flow and production in patients with normal pressure hydrocephalus studied by MRI. Neuroradiology 1994, 36:210-215.

128. Kim DS, Choi JU, Huh R, Yun PH, Kim DI: Quantitative assessment of cerebrospinal fluid hydrodynamics using a phase-contrast cine MR image in hydrocephalus. Childs Nerv Syst 1999, 15:461-467.

129. Bradley WG Jr, Scalzo D, Queralt J, Nitz WN, Atkinson DJ, Wong P: Normalpressure hydrocephalus: evaluation with cerebrospinal fluid flow measurements at MR imaging. Radiology 1996, 198:523-529.

130. Tullberg M, Mansson JE, Fredman P, Lekman A, Blennow K, Ekman R, Rosengren LE, Tisell M, Wikkelso C: CSF sulfatide distinguishes between normal pressure hydrocephalus and subcortical arteriosclerotic encephalopathy. J Neurol Neurosurg Psychiatry 2000, 69:74-81.

131. McCormick JM, Yamada K, Rekate HL, Miyake H: Time course of intraventricular pressure change in a canine model of hydrocephalus: its relationship to sagittal sinus elastance. Pediatr Neurosurg 1992, 18:127-133.

132. Olivero WC, Rekate HL, Chizeck HJ, Ko W, McCormick JM: Relationship between intracranial and sagittal sinus pressure in normal and hydrocephalic dogs. Pediatr Neurosci 1988, 14:196-201.

133. Algin O, Hakyemez B, Ocakoglu G, Parlak M: MR cisternography: is it useful in the diagnosis of normal-pressure hydrocephalus and the selection of "good shunt responders"? Diagn Interv Radiol 2011, 17:105-111.

134. Tator CH, Fleming JF, Sheppard RH, Turner VM: A radioisotopic test for communicating hydrocephalus. J Neurosurg 1968, 28:327-340.

135. Wuerfel J, Paul F, Zipp F: Cerebral blood perfusion changes in multiple sclerosis. J Neurol Sci 2007, 259:16-20

136. McDonald WI, Compston A, Edan G, Goodkin D, Hartung HP, Lublin FD, McFarland HF, Paty DW, Polman CH, Reingold SC, Sandberg-Wollheim M, Sibley W, Thompson A, van den Noort S, Weinshenker BY, Wolinsky JS: Recommended diagnostic criteria for multiple sclerosis: guidelines from the International Panel on the Diagnosis of Multiple Sclerosis. Ann Neurol 2001, 50:121-127.

137. Hulst HE, Geurts JJ: Gray matter imaging in multiple sclerosis: what have we learned? BMC Neurol 2011, 11:153

138. Minagar A, Alexander SJ: Blood-brain barrier disruption in multiple sclerosis. Mult Scler 2003, 9:540-549.

139. Kirk J, Plumb J, Mirakhur M, McQuaid S: Tight junctional abnormality in multiple sclerosis white matter affects all calibres of vessel and is associated with blood-brain barrier leakage and active demyelination. J Pathol 2003, 201:319-327.

140. Wakefield AJ, More LJ, Difford J, McLaughlin JE: Immunohistochemical study of vascular injury in acute multiple sclerosis. J Clin Pathol 1994, 47:129-133.

141. Aboul-Enein F, Lassmann H: Mitochondrial damage and histotoxic hypoxia: a pathway of tissue injury in inflammatory brain disease? Acta Neuropathol 2005, 109:49-55.

142. Ge Y, Zohrabian VM, Grossman RI: Seven-Tesla magnetic resonance imaging: new vision of microvascular abnormalities in multiple sclerosis. Arch Neurol 2008, 65:812-816

143. Werring DJ, Brassat D, Droogan AG, Clark CA, Symms MR, Barker GJ, MacManus DG, Thompson AJ, Miller DH: The pathogenesis of lesions and normal-appearing white matter changes in multiple sclerosis: a serial diffusion MRI study. Brain 2000, 123:1667-1676.

144. Wuerfel J, Bellmann-Strobl J, Brunecker P, Aktas O, McFarland H, Villringer A, Zipp F: Changes in cerebral perfusion precede plaque formation in multiple sclerosis: a longitudinal perfusion MRI study. Brain 2004, 127:111-119.

145. Lochhead JJ, McCaffrey G, Quigley CE, Finch J, DeMarco KM, Nametz N, Davis TP: Oxidative stress increases blood-brain barrier permeability and induces alterations in occludin during hypoxia-reoxygenation. J Cereb Blood Flow Metab 2010, 30:1625-1636.

146. Witt KA, Mark KS, Hom S, Davis TP: Effects of hypoxia-reoxygenation on rat blood-brain barrier permeability and tight junctional protein expression. Am J Physiol Heart Circ Physiol 2003, 285:H2820-H2831.
147. Witt KA, Mark KS, Sandoval KE, Davis TP: Reoxygenation stress on blood-brain barrier paracellular permeability and edema in the rat. Microvasc Res 2008, 75:91-96.

148. Plumb J, McQuaid S, Mirakhur M, Kirk J: Abnormal endothelial tight junctions in active lesions and normal-appearing white matter in multiple sclerosis. Brain Pathol 2002, 12:154-169.

149. Leech S, Kirk J, Plumb J, McQuaid S: Persistent endothelial abnormalities and blood-brain barrier leak in primary and secondary progressive multiple sclerosis. Neuropathol Appl Neurobiol 2007, 33:86-98.

150. Kobari M, Meyer JS, Ichijo M, Oravez WT: Leukoaraiosis: correlation of MR and CT findings with blood flow, atrophy, and cognition. AJNR Am J Neuroradiol 1990, 11:273-281.

151. Schmidt R, Enzinger C, Ropele S, Schmidt H, Fazekas F: Subcortical vascular cognitive impairment: similarities and differences with multiple sclerosis. J Neurol Sci 2006, 245:3-7.

152. Graumann U, Reynolds R, Steck AJ, Schaeren-Wiemers N: Molecular changes in normal appearing white matter in multiple sclerosis are characteristic of neuroprotective mechanisms against hypoxic insult. Brain Pathol 2003, 13:554-573.

153. Fernando MS, Simpson JE, Matthews F, Brayne C, Lewis CE, Barber R, Kalaria RN, Forster G, Esteves F, Wharton SB, Shaw PJ, O'Brien JT, Ince PG, MRC Cognitive Function and Ageing Neuropathology Study Group: White matter lesions in an unselected cohort of the elderly: molecular pathology suggests origin from chronic hypoperfusion injury. Stroke 2006, 37:1391-1398.

154. ten Dam VH, van den Heuvel DM, de Craen AJ, Bollen EL, Murray HM, Westendorp RG, Blauw GJ, van Buchem MA: Decline in total cerebral blood flow is linked with increase in periventricular but not deep white matter hyperintensities. Radiology 2007, 243:198-203.

155. Schlesinger $B$ : The venous drainage of the brain, with special reference to the galenic system. Brain 1939, 62:274-291.

156. San Millan Ruiz D, Delavelle J, Yilmaz H, Gailloud P, Piovan E, Bertramello A Pizzini F, Rufenacht DA: Parenchymal abnormalities associated with developmental venous anomalies. Neuroradiology 2007, 49:987-995.

157. Dillon WP: Cryptic vascular malformations: controversies in terminology, diagnosis, pathophysiology, and treatment. AJNR Am J Neuroradiol 1997, 18:1839-1846

158. Luce JM, Huseby JS, Kirk W, Butler J: A Starling resistor regulates cerebral venous outflow in dogs. J Appl Physiol 1982, 53:1496-1503.

159. Vignes JR, Dagain A, Guerin J, Liguoro D: A hypothesis of cerebral venous system regulation based on a study of the junction between the cortical bridging veins and the superior sagittal sinus. Laboratory investigation. J Neurosurg 2007, 107:1205-1210.

160. Holt JP: The collapse factor in the measurement of venous pressure. Am J Physiol 1941, 134:292-299.

161. Katz Al, Chen Y, Moreno AH: Flow through a collapsible tube. Experimental analysis and mathematical model. Biophys J 1969, 9:1261-1279.

162. Lyon CK, Scott JB, Anderson DK, Wang CY: Flow through collapsible tubes at high Reynolds numbers. Circ Res 1981, 49:988-996.

163. Lyon CK, Scott JB, Wang CY: Flow through collapsible tubes at low Reynolds numbers. Applicability of the waterfall model. Circ Res 1980, 47:68-73.

164. Schaller B: Physiology of cerebral venous blood flow: from experimental data in animals to normal function in humans. Brain Res Brain Res Rev 2004, 46:243-260.

165. Zamboni P, Galeotti R, Menegatti E, Malagoni AM, Gianesini S, Bartolomei I, Mascoli F, Salvi F: A prospective open-label study of endovascular treatment of chronic cerebrospinal venous insufficiency. J Vasc Surg 2009, 50:1348-1358. e1341-1343.

166. Egnor M, Rosiello A, Zheng L: A model of intracranial pulsations. Pediatr Neurosurg 2001, 35:284-298.

167. Wagshul ME, Eide PK, Madsen JR: The pulsating brain: a review of experimental and clinical studies of intracranial pulsatility. Fluids Barriers CNS 2011, 8:5.

168. Kim J, Thacker NA, Bromiley PA, Jackson A: Prediction of the jugular venous waveform using a model of CSF dynamics. AJNR Am J Neuroradiol 2007, 28:983-989.

169. Ambarki K, Baledent O, Kongolo G, Bouzerar R, Fall S, Meyer ME: A new lumped-parameter model of cerebrospinal hydrodynamics during the cardiac cycle in healthy volunteers. IEEE Trans Biomed Eng 2007, 54:483-491 
170. Alperin N, Vikingstad EM, Gomez-Anson B, Levin DN: Hemodynamically independent analysis of cerebrospinal fluid and brain motion observed with dynamic phase contrast MRI. Magn Reson Med 1996, 35:741-754.

171. Kitano M, Oldendorf WH, Cassen B: The elasticity of the cranial blood pool. J NuCl Med 1964, 5:613-625

172. Zamboni P, Galeotti R: The chronic cerebrospinal venous insufficiency syndrome. Phlebology 2010, 25:269-279

173. Doepp F, Paul F, Valdueza JM, Schmierer K, Schreiber SJ: No cerebrocervical venous congestion in patients with multiple sclerosis. Ann Neurol 2010, 68:173-183.

174. Beggs CB: Multiple sclerosis appears to be associated with cerebral venous abnormalities. Ann Neurol 2010, 68:560-561.

175. Doepp F, Wurfel JT, Pfueller CF, Valdueza JM, Petersen D, Paul F, Schreiber SJ: Venous drainage in multiple sclerosis: a combined MRI and ultrasound study. Neurology 2011, 77:1745-1751.

176. Mayer CA, Pfeilschifter W, Lorenz MW, Nedelmann M, Bechmann I, Steinmetz H, Ziemann U: The perfect crime? CCSVI not leaving a trace in MS. J Neurol Neurosurg Psychiatry 2011, 82:436-440.

177. Khan O, Filippi M, Freedman MS, Barkhof F, Dore-Duffy P, Lassmann H, Trapp B, Bar-Or A, Zak I, Siegel MJ, Lisak R: Chronic cerebrospinal venous insufficiency and multiple sclerosis. Ann Neurol 2010, 67:286-290.

178. Wattjes MP, Doepp F, Bendszus M, Fiehler J: Chronic cerebrospinal venous insufficiency" in multiple sclerosis - is multiple sclerosis a disease of the cerebrospinal venous outflow system? Rofo 2011, 183:523-530.

179. Baracchini C, Atzori M, Gallo P: CCSVI and MS: no meaning, no fact. Neurol Sci 2012. Epub ahead of print.

180. Zivadinov R, Marr K, Cutter G, Ramanathan M, Benedict RH, Kennedy C, Elfadil M, Yeh AE, Reuther J, Brooks C, Hunt K, Andrews M, Carl E, Dwyer MG, Hojnacki D, Weinstock-Guttman B: Prevalence, sensitivity, and specificity of chronic cerebrospinal venous insufficiency in MS. Neurology 2011, 77:138-144.

181. Simka M, Kostecki J, Zaniewski M, Majewski E, Hartel M: Extracranial Doppler sonographic criteria of chronic cerebrospinal venous insufficiency in the patients with multiple sclerosis. Int Angiol 2010, 29:109-114.

182. Zaniewski M, Kostecki J, Kuczmik W, Ziaja D, Opala G, Swiat M, Korzeniowski T, Majewski E, Urbanek T, Pawlicki K: Neck duplex Doppler ultrasound evaluation for assessing chronic cerebrospinal venous insufficiency in multiple sclerosis patients. Phlebology 2012. Epub ahead of print.

183. Utriainen D, Feng W, Elias S, Latif Z, Hubbard D, Haacke EM: Using magnetic resonance imaging as a means to study chronic cerebral spinal venous insufficiency in multiple sclerosis patients. Tech Vasc Interv Radiol 2012, 15:101-112.

184. Haacke EM, Feng W, Utriainen D, Trifan G, Wu Z, Latif Z, Katkuri Y, Hewett J, Hubbard D: Patients with multiple sclerosis with structural venous abnormalities on MR imaging exhibit an abnormal flow distribution of the internal jugular veins. J Vasc Interv Radiol 2012, 23:60-68. e61-63.

185. Yamout B, Herlopian A, Issa Z, Habib RH, Fawaz A, Salame J, Wadih A, Awdeh $\mathrm{H}$, Muallem N, Raad R, Al-Kutoubi A: Extracranial venous stenosis is an unlikely cause of multiple sclerosis. Mult Scler 2010, 16:1341-1348.

186. Bastianello S, Romani A, Viselner G, Tibaldi EC, Giugni E, Altieri M, Cecconi $P$, Mendozzi L, Farina M, Mariani D, Galassi A, Quattrini C, Mancini M, Bresciamorra V, Lagace A, McDonald S, Bono G, Bergamaschi R: Chronic cerebrospinal venous insufficiency in multiple sclerosis: clinical correlates from a multicentre study. BMC Neurol 2011, 11:132.

187. Krogias C, Schroder A, Wiendl H, Hohlfeld R, Gold R: Chronic cerebrospinal venous insufficiency" and multiple sclerosis: critical analysis and first observation in an unselected cohort of MS patients. Nervenarzt 2010, 81:740-746

188. Baracchini C, Perini P, Causin F, Calabrese M, Rinaldi F, Gallo P: Progressive multiple sclerosis is not associated with chronic cerebrospinal venous insufficiency. Neurology 2011, 77:844-850.

189. Wattjes MP, van Oosten BW, de Graaf WL, Seewann A, Bot JC, van den Berg R, Uitdehaag BM, Polman CH, Barkhof F: No association of abnormal cranial venous drainage with multiple sclerosis: a magnetic resonance venography and flow-quantification study. J Neurol Neurosurg Psychiatry 2011, 82:429-435.

190. Sundstrom P, Wahlin A, Ambarki K, Birgander R, Eklund A, Malm J: Venous and cerebrospinal fluid flow in multiple sclerosis: a case-control study. Ann Neurol 2010, 68:255-259.
191. Centonze D, Floris R, Stefanini M, Rossi S, Fabiano S, Castelli M, Marziali S, Spinelli A, Motta C, Garaci FG, Bernardi G, Simonetti G: Proposed chronic cerebrospinal venous insufficiency criteria do not predict multiple sclerosis risk or severity. Ann Neurol 2011, 70:51-58

192. Laupacis A, Lillie E, Dueck A, Straus S, Perrier L, Burton JM, Aviv R, Thorpe K, Feasby T, Spears J: Association between chronic cerebrospinal venous insufficiency and multiple sclerosis: a meta-analysis. CMAJ 2011, 183:E1203-E1212.

193. Parvey HR, Eisenberg RL, Giyanani V, Krebs CA: Duplex sonography of the portal venous system: pitfalls and limitations. AJR Am J Roentgenol 1989, 152:765-770.

194. Taffoni MJ, Ravenel JG, Ackerman SJ: Prospective comparison of indirect CT venography versus venous sonography in ICU patients. AJR Am J Roentgenol 2005, 185:457-462.

195. Menegatti E, Genova V, Tessari M, Malagoni AM, Bartolomei I, Zuolo M, Galeotti R, Salvi F, Zamboni P: The reproducibility of colour Doppler in chronic cerebrospinal venous insufficiency associated with multiple sclerosis. Int Angiol 2010, 29:121-126.

196. Monti L, Menci E, Ulivelli M, Cerase A, Bartalini S, Piu P, Marotti N, Leonini S, Galluzzi P, Romano DG, Casasco AE, Venturi C: Quantitative ColourDopplerSonography evaluation of cerebral venous outflow: a comparative study between patients with multiple sclerosis and controls. PLOS One 2011, 6:e25012.

197. Zamboni P, Consorti G, Galeotti R, Gianesini S, Menegatti E, Tacconi G, Carinci F: Venous collateral circulation of the extracranial cerebrospinal outflow routes. Curr Neurovasc Res 2009, 6:204-212.

198. Higgins JN, Pickard JD: Lateral sinus stenoses in idiopathic intracranial hypertension resolving after CSF diversion. Neurology 2004, 62:1907-1908.

199. Higgins JN, Owler BK, Cousins C, Pickard JD: Venous sinus stenting for refractory benign intracranial hypertension. Lancet 2002, 359:228-230.

200. Moyer JH, Miller SI, Snyder H: Effect of increased jugular pressure on cerebral hemodynamics. J Appl Physiol 1954, 7:245-247.

201. Chai PJ, Skaryak LA, Ungerleider RM, Greeley WJ, Kern FH, Schulman SR, Hansell DR, Auten RL, Mahaffey SF, Meliones JN: Jugular ligation does not increase intracranial pressure but does increase bihemispheric cerebral blood flow and metabolism. Crit Care Med 1995, 23:1864-1871.

202. Bateman GA: Arterial inflow and venous outflow in idiopathic intracranial hypertension associated with venous outflow stenoses. J Clin Neurosci 2008, 15:402-408.

doi:10.1186/1741-7015-11-142

Cite this article as: Beggs: Venous hemodynamics in neurological disorders: an analytical review with hydrodynamic analysis. BMC Medicine 2013 11:142

\section{Submit your next manuscript to BioMed Central and take full advantage of:}

- Convenient online submission

- Thorough peer review

- No space constraints or color figure charges

- Immediate publication on acceptance

- Inclusion in PubMed, CAS, Scopus and Google Scholar

- Research which is freely available for redistribution 